ESTUDIO

\title{
REFORMA DE LA INSTITUCIONALIDAD AMBIENTAL: PROBLEMAS Y OPORTUNIDADES*
}

\author{
Lucas Sierra
}

En este trabajo se examina críticamente la reforma del diseño institucional del medio ambiente que ha iniciado el Gobierno. El análisis distingue entre las tres dimensiones en que suele dividirse la regulación ambiental: definición de política y normas ambientales, gestión y fiscalización.

Si bien la regulación ambiental chilena ha operado básicamente bien desde que fue establecida en 1994, en este trabajo se sostiene que requiere mejoras en las tres dimensiones recién mencionadas.

Para la definición de política y normas ambientales, el proyecto sugiere la creación de un Ministerio del Medio Ambiente. Ésta es la peor parte de la iniciativa, pues elimina el escenario multilateral que posibilita el equilibrio de objetivos e intereses necesario en la defini-

LuCas Sierra I. Abogado, Universidad de Chile. LL. M. Universidad de Yale. Ph. D. Universidad de Cambridge. Profesor de Derecho, Universidad de Chile. Investigador del Centro de Estudios Públicos (CEP).

* Para escribir este trabajo me he beneficiado de conversaciones con Gabriel del Fávero, Ricardo Katz, Leonel Sierralta, Javier Vergara, Jorge Bermúdez, Luis Cordero y Jaime Dinamarca. A su vez, Harald Beyer y Arturo Fontaine T. hicieron interesantes observaciones a una versión anterior, que agradezco mucho. También agradezco a Lucas Mac Clure (ayudante de investigación del CEP), por su enorme ayuda, tan amable como aguda; sin ella, este trabajo difícilmente se hubiera hecho. Sobra decir que ninguno de ellos tiene responsabilidad alguna por los errores u omisiones que puedan haber quedado.

Estudios Públicos, 111 (invierno 2008). 
ción de la política y las normas ambientales. Para la gestión ambiental, en especial respecto del mecanismo de evaluación de impacto ambiental, el proyecto propone un servicio sujeto al Sistema de Alta Dirección Pública. Parece una buena idea, aunque, como está formulada, arriesga centralizar y dificultar la toma de decisiones. Para la fiscalización, en fin, propone una Superintendencia. Aunque es un paso en la dirección correcta, no está suficientemente dado.

A la luz de esta crítica, el trabajo concluye con una propuesta alternativa de diseño institucional que, en línea con buena parte de las evaluaciones chilenas y extranjeras disponibles, permita aprovechar bien la oportunidad de mejora que se ha abierto con la presentación del proyecto de ley. Esta propuesta se basa en una premisa básica de economía institucional: en un escenario abigarrado y superpuesto como el que hoy tenemos en materias ambientales, cualquier competencia que se cree debe reemplazar a una existente.

\section{INTRODUCCIÓN}

\section{Н}

ste trabajo analiza críticamente la reforma que el Gobierno ha propuesto para mejorar el diseño institucional del medio ambiente que fue establecido en 1994 por la Ley 19.300 sobre Bases Generales del Medio Ambiente. El Gobierno presentó un proyecto de ley con modificaciones a las tres dimensiones de este diseño institucional: definición de política y normas ambientales, gestión ambiental y fiscalización ${ }^{1}$. La regulación ambiental necesita mejoras, eso nadie lo duda, y las necesita en estas tres dimensiones. Pero la reforma propuesta por el Gobierno, sostiene este trabajo, no las encara igualmente bien, desaprovechando la oportunidad de mejora que ha abierto.

Respecto de la política y normas ambientales, el proyecto de ley no es acertado. Hace algo que prácticamente ninguna de las evaluaciones, chilenas y extranjeras, ha recomendado hacer: crear un Ministerio del Medio Ambiente. Casi todas ellas han propuesto sacarle más partido al modelo de coordinación entre distintos Ministerios con competencias ambientales que

${ }^{1}$ Se trata de la iniciativa que "Crea el Ministerio del Medio Ambiente, el Servicio de Evaluación Ambiental y la Superintendencia del Medio Ambiente”, Boletín 5947-12, ingresado a la Cámara de Diputados el 3 de julio de 2008. En adelante, "el proyecto de ley”. 
hoy existe para definir la política y normas ambientales ${ }^{2}$. El proyecto de ley quiere hacerlo mediante un Ministerio del Medio Ambiente. No parece una buena idea, pues el modelo de coordinación vigente descansa, precisamente, sobre la inexistencia de un "sector" medioambiental a cargo de un Ministerio del ramo. Para más remate, junto con crear este Ministerio, el proyecto de ley hace desaparecer el escenario multilateral en que esa coordinación entre Ministerios es posible: el Consejo Directivo de la Conama. Propone, en cambio, una relación bilateral entre el Ministerio del Medio Ambiente y cada uno de los Ministerios sectoriales. De seguro, esto generará situaciones de "gallito" en cada negociación sobre política y normas ambientales, constituyéndose en un potencial dolor de cabeza constante para la Presidencia de la República. Esas situaciones de "gallito", además, se verán incentivadas por la amplísima definición de "medio ambiente" que da la Ley 19.300. Esta amplitud facilita la superposición de ámbitos de competencia. No es un escenario muy apto para la coordinación multisectorial.

Ahora bien, la alternativa no es un Ministerio del Medio Ambiente que, concentrando todas las competencias ambientales hoy dispersas, elimine la lógica de coordinación. Eso tampoco sería acertado, pues la política y normas ambientales requieren reflejar el balance de un conjunto de objetivos e intereses distintos y, en algún punto, potencialmente contradictorios. Por esto la lógica de coordinación es valiosa: permite que esos intereses se pesen recíprocamente. Esto explica, además, el hecho de que casi todas las sugerencias para mejorar nuestra política y normas ambientales no contemplen la creación de un Ministerio del Medio Ambiente. Sí contemplan, en cambio, reducir el Consejo Directivo de la Conama para que, reflejando los distintos intereses que deben contrapesarse, sea más operativo que el actual. Este trabajo también se inclina por esta alternativa.

\footnotetext{
${ }^{2}$ Este modelo de coordinación fue una decisión deliberada de los órganos colegisladores, quienes rechazaron la posibilidad de un Ministerio del Medio Ambiente. Así lo expresa bien el Mensaje con que en 1992 el gobierno del Presidente Aylwin mandó al Congreso el proyecto que dos años más tarde se convertiría en la ley vigente: "Honorable Senado: [....] Dada esta realidad y la experiencia internacional, la institucionalidad ambiental debe desarrollarse sobre dos bases. Por una parte, reconocer las competencias ambientales de los distintos ministerios y servicios, involucrándolos en los temas ambientales en que, por sus respectivas esferas de competencia, les corresponde conocer. Por otra, generando una capacidad de coordinación al interior del Poder Ejecutivo. Restarles competencia para radicar el tema ambiental en una sola institución, que era una de las opciones a considerar, es, a nuestro juicio, inviable y poco realista, ya que implica reestructurar íntegramente el aparataje público a un costo injustificado frente a la capacidad institucional instalada. Ella, debidamente coordinada, puede accionar eficazmente". En "Mensaje de S. E. el Presidente de la República con el que inicia un proyecto de ley de Bases del Medio Ambiente”, Santiago, septiembre 14 de 1992 (Mensaje NNo 387-324). Énfasis agregado.
} 
Sobre la gestión ambiental, el proyecto de ley parece acertado en un aspecto de ella y muy insuficiente en otro. Puede ser acertado respecto del Sistema de Evaluación Ambiental, al convertirlo en un servicio sujeto al Sistema de Alta Dirección Pública. El problema es que centraliza mucho el proceso de evaluación ambiental, pues saca todos los representantes locales que participan hoy. Quizás sea bueno cambiar algunos, pero debería dejarse una cierta representación local. Mal que mal, se trata de decisiones que pueden reportar beneficios para la región, pero también costos.

El otro aspecto de la gestión ambiental son los recursos naturales. Hay un muy extendido consenso en que la gestión de estos recursos no se hace bien en Chile. Aquí hay mucha necesidad y espacio de mejora. El proyecto de ley, sin embargo, hace poco y nada al respecto y peca de grave omisión. Siguiendo algunas propuestas chilenas y extranjeras, este trabajo propone la creación de un Ministerio de Recursos Naturales Renovables, que reemplace al actual Ministerio de Bienes Nacionales y absorba todas las competencias de protección que hoy se dispersan en algunos Ministerios sectoriales. Si se necesita un Ministerio, es uno de Recursos Naturales, no de Medio Ambiente. Naturalmente, se propone que este Ministerio integre el grupo multisectorial reducido que se propone para la política y normas ambientales. También se propone que el servicio a cargo de la evaluación ambiental pueda conectarse con la Presidencia de la República a través de este Ministerio. Lo mismo la Superintendencia de que se trata a continuación.

En fin, la propuesta del proyecto de ley sobre fiscalización es acertada: crear una Superintendencia. Sin embargo, es una Superintendencia muy débil en su ámbito de competencia, pues, junto con crearla, deja vivas las competencias de fiscalización ambiental que hoy tienen varios Ministerios sectoriales. Como la fiscalización es una tarea de aplicación y no de creación de normas, este trabajo sostiene que puede concentrarse en un solo órgano bien diseñado. El proyecto de ley las concentra muy a medias, superponiendo la Superintendencia a los ámbitos de competencia sectoriales que hoy fiscalizan. Esto va a generar roces institucionales. Con ciertos requisitos de procedimiento, este trabajo recomienda sacar todas las competencias de fiscalización ambiental que hoy están distribuidas en distintos Ministerios y entregárselas a la Superintendencia. Así se aprovecharía mejor el buen paso que el Gobierno está dando para mejorar esta fiscalización.

Para desplegar este argumento, el trabajo se divide en cuatro partes. En las tres primeras se pasa revista a nuestra experiencia regulatoria ambiental, según evaluaciones que de ella se han hecho en Chile y en el extranjero. Para esto se usan las tres dimensiones de la regulación ambiental señaladas: 
política y normas ambientales (1), gestión ambiental (2) y fiscalización (3). En cada una de éstas se analizan críticamente las respectivas propuestas que hace el proyecto de ley. A la luz de esta crítica, en (4) se propone una alternativa a la reforma que ha iniciado el proyecto de ley, distinguiendo, una vez más, entre las tres dimensiones de la regulación ambiental. A juicio de este trabajo, esta alternativa aprovecharía la oportunidad de mejora que el Gobierno ha abierto con su proyecto de ley, sin los problemas que éste tiene. Con esto se concluye.

\section{DEFINICIÓN DE LA POLÍTICA Y NORMAS AMBIENTALES}

\subsection{Evaluaciones nacionales y extranjeras}

Aquí la crítica básica ha estado dirigida al Consejo de Ministros por no haber ejercido en toda su extensión la competencia de política pública y definición de criterios normativos que posee ${ }^{3}$. Pareciera que este Consejo se ha dedicado a las reclamaciones que debe conocer en el procedimiento de evaluación de impacto ambiental, pero no a ejercer su competencia normativa. Hay mucho SEIA, se dice, y pocas normas. Y esto, probablemente, se explica en parte por una prioridad relativamente baja del medio ambiente en la política gubernativa ${ }^{4}$.

La falta de normas se suple con la discrecionalidad de quienes deben aplicarlas, por ejemplo, en el mecanismo de evaluación de impacto ambiental o en los procedimientos de fiscalización. Esto, sabemos, genera incertidumbre. Y puede generar arbitrariedad.

Rafael Asenjo, uno de los autores del diseño institucional establecido en 1994, sintetiza así esta crítica a la débil tarea normativa del Consejo de Ministros de la Conama:

El Consejo Directivo tuvo un funcionamiento esporádico e irregular, sin que se viera a sus integrantes adoptar decisiones de políticas ambientales de alto impacto para ser implementadas y monitoreadas con posterioridad [...] los ministros de la Segpres no se destacaron mayormente como portavoces políticos de la necesidad de incorporar los criterios de

\footnotetext{
${ }^{3}$ Para una descripción del mecanismo generador de normas ambientales vigente, véase Del Fávero y Katz (1998).

${ }^{4}$ Esto no debería sorprender mucho si, por ejemplo, se consideran las encuestas del CEP. A juzgar por ellas, la ciudadanía parece no pensar en el medio ambiente como un problema al cual el Gobierno debería destinar sus mejores esfuerzos en solucionar. Por el contrario, siempre aparece con una prioridad muy baja.
} 
sustentabilidad de la gestión ambiental a las consideraciones políticas y económicas de la acción global del Gobierno. Su rol, más bien formal, no incluyó ni la efectiva coordinación de la acción sectorial ni el monitoreo o seguimiento de las decisiones adoptadas. (Asenjo, 2006: 11.)

Además hace una crítica a la también insuficiente tarea desplegada por la Dirección Ejecutiva de la Conama: “[...] la Dirección Ejecutiva de la Conama tampoco se destacó por la generación de comités operativos interministeriales, como una manera central de llevar a cabo su tarea de activar internamente el sistema de gestión pública. Marcada por un carácter concentrador, su acción por desgracia se vio fuertemente focalizada en la preparación de algunos Reglamentos de la Ley 19.300, particularmente el del Sistema de Evaluación de Impacto Ambiental (SEIA)” (Asenjo, 2006: 11-12).

La base de estas críticas, constituida por la percepción de que hay una capacidad instalada ociosa en el diseño vigente, explica el hecho de que, en general, las propuestas de mejora para la formulación de política y normas han apuntado a reforzar el mecanismo de coordinación existente, y no a reemplazarlo. A fin de reforzarlo, se ha propuesto reducir el número de Ministerios involucrados para que, sin descuidar la mirada sistémica que debe tener la definición de la política ambiental, se facilite el trabajo colegiado del Consejo Directivo. También se ha propuesto concentrar el trabajo de este Consejo en la definición de política y en el dictado de normas, liberándolo de sus tareas como instancia de reclamación en el SEIA.

Un buen ejemplo de lo anterior es el Informe Jadresic (Jadresic et al., 1998), que contiene las conclusiones y recomendaciones de la "Comisión Presidencial de Modernización de la Institucionalidad Reguladora del Estado”. Éste contiene el primer diagnóstico crítico de carácter sistemático hecho a la regulación ambiental ${ }^{5}$. El Informe ve en el diseño actual las siguientes dos necesidades:

- Lograr una diferenciación adecuada entre los órganos que se responsabilizan de la función normativa y los que aplican regulación.

- $\quad$ Lograr que a nivel del proceso normativo y de definición de políticas se identifiquen más claramente los ámbitos y criterios de acción del Estado en diversos sectores con características comunes (Informe Jadresic: 95).

${ }^{5}$ El Presidente de la Comisión fue Alejandro Jadresic, de ahí el nombre por el que comúnmente se le conoce. Estuvo integrada, además, por Vivianne Blanlot y Gregorio San Martín (Informe Jadresic, Jadresic et al., 1998: i). 
A la luz de estas necesidades, y respecto de la definición de política ambiental y de las normas, el Informe mantiene el sistema Conama-Corema, con algunas modificaciones en la integración del Consejo de Ministros, reduciéndolo, y en su competencia, al limitarla a la definición de política y normas, sin participar del procedimiento SEIA. Dice al respecto:

Quedan como responsabilidades exclusivas de la Comisión la definición de políticas ambientales, la elaboración y proposición [a la Presidencia de la República] de leyes y reglamentos de carácter ambiental, la elaboración y proposición de normas de calidad y emisión, y la elaboración y proposición de planes de prevención y descontaminación. (Informe Jadresic: 96.)

Así, desde el punto de vista de la política y de las normas ambientales, el Consejo de Ministros sigue siendo el órgano directivo a nivel nacional, pero se reduce el número de los ministros que lo integran de los actuales 14 a los siguientes seis: Interior, Secretaría General de la Presidencia, Economía, Hacienda, Salud y el nuevo que esta propuesta sugiere: de Recursos Naturales Renovables, como se verá más abajo. Esta estructura se repite regionalmente en las Corema, las cuales tienen a cargo la definición de la política ambiental en las regiones, conforme a lo dispuesto a nivel nacional por la Conama. Las Corema están integradas por el Intendente, que las preside, los Seremi de Economía, Salud, del nuevo de Recursos Naturales Renovables y un representante de la Secretaría Ejecutiva de la Conama, como secretario ejecutivo. Toda esta estructura es asesorada técnicamente por una Secretaría Ejecutiva, como dice la ley actual.

El Informe Jadresic se preguntó por la posibilidad de crear un Ministerio del Medio Ambiente para que se hiciera cargo de la definición de la política ambiental. Sin embargo, como había ocurrido al dictarse la ley cuatro años antes, la idea fue de nuevo expresamente desechada.

Esto, pues se consideró que, a la hora de fijar la política sobre el medio ambiente, el diseño institucional debía facilitar una visión de conjunto, multisectorial. Dice el Informe:

En los próximos años el desarrollo de políticas ambientales y de normativa requerirá de un esfuerzo sustantivo de integración de las visiones de protección de la salud y de los recursos, con las de eficiencia económica y productiva; del desarrollo de instrumentos económicos de gestión ambiental; y de una adecuada priorización de las políticas ambientales en las finanzas públicas. Por ello, se consideró que el proceso 
normativo debe involucrar formalmente a las máximas autoridades de salud, de protección de los recursos naturales, de la economía, de las finanzas públicas y de la administración pública, para asegurar el equilibrio y la viabilidad de las políticas ambientales. (Informe Jadresic: 96-97.)

Este Informe, entonces, desecha la creación de un Ministerio del Medio Ambiente para la definición de la política ambiental. Sí propone, en cambio, darle a la Conama un Presidente y darle rango ministerial. Esto iba a ocurrir nueve años después: en marzo del año 2007 se dictó la Ley 20.173 que creó el cargo de Presidente de la Conama y le dio el rango de ministro. Y sí propone la creación de un Ministerio, pero no de Medio Ambiente, sino que de Recursos Naturales. A esto último volveremos al tratar de la gestión ambiental más abajo.

La lógica de coordinación de la regulación vigente, que expresa la idea de que la política ambiental y sus criterios normativos deben tener un carácter multisectorial, sistémico, no sólo ha sido subrayada por el Informe Jadresic, sino que también por otras varias evaluaciones que se han hecho de la regulación chilena. Un buen ejemplo es otro informe, del año 2000, el Informe Castillo.

El Informe Castillo (Castillo et al., 2000) fue encargado por la Dirección Ejecutiva de la Conama a Marcelo Castillo y está fundamentalmente basado en las opiniones de una comisión conformada mayoritariamente por abogados especialistas en derecho ambiental ${ }^{6}$. En materia de diseño institucional, el Informe señala: "No hubo una proposición única de la Comisión en materia de institucionalidad ambiental”, pero que la mayoría estuvo por “avanzar en el perfeccionamiento del actual modelo coordinador” (Informe Castillo: 64-65).

${ }^{6}$ Sus integrantes fueron las siguientes personas: Adriana Hoffmann, Directora Ejecutiva de Conama (Presidenta de la Comisión); Álvaro Sapag, Fiscal de Conama (Coordinador); Marcelo Castillo, abogado, consultor externo de Conama (Secretario Técnico); Patricio Rodrigo, María Luisa Robleto, Dra. Patricia Frenz Yonechi, Rayén Quiroga, todos asesores de la Dirección Ejecutiva de Conama; Eduardo Astorga, Raúl Campusano, Luis Cordero, Gonzalo Cubillos, Gabriel del Fávero, Jaime Dinamarca, Fernando Dougnac, Pedro Fernández, Andrés Gómez-Lobo, Sergio Praus, José Agustín Ramírez, Fernando Toledo, Walter Traub, Javier Vergara, Sergio Vergara, Juan Carlos Urquidi y Sergio Montenegro, todos abogados especialistas en Derecho Ambiental, y Cristóbal Fernández, representante del Ministerio de Vivienda y Urbanismo, y Antonia Urrejola, del Comité de Modernización del Estado. El Informe aclara que en las reuniones de la Comisión "la asistencia de los funcionarios de Conama que integraban la Comisión fue baja, con la excepción de los señores Patricio Rodrigo y Álvaro Sapag. Asimismo, sólo asistió a 2 reuniones la Sra. Antonia Urrejola del Comité de Modernización del Estado". Castillo et al. (2000), p. 29. Así, la comisión en los hechos funcionó la mayor parte del tiempo con integrantes hombres. Esto explica por qué es informalmente conocida como "Club de Tobi”. 
Para hacer esto, propuso:

- $\quad$ Disminuir el número de Ministerios que forman parte del Consejo Directivo, a fin de facilitar su trabajo, aunque, a diferencia del Informe Jadresic, no dice cuáles Ministerios deberían quedar y cuáles salir.

- $\quad$ Sacar del Consejo Directivo las responsabilidades por la gestión de la Conama que hoy tiene y entregárselas a la Dirección Ejecutiva7 .

- Reformar las Corema en el sentido de eliminar de ellas a los integrantes que definió como puramente “políticos”, como Gobernadores, Consejeros Regionales y Seremi cuyos Ministerios integran el Consejo Directivo de la Conama, pero que no tienen competencias ambientales reales en la Región (como, por ejemplo, Defensa). En su lugar, se propuso incorporar a los Directores Regionales de los servicios públicos que tienen competencia en materia de medio ambiente, incluido el Gobernador Marítimo correspondiente. En otras palabras, traslada al interior de las Corema a los "Comités Técnicos" que hoy existen en las regiones, y que son asesores externos de las Corema ${ }^{8}$.

De este modo, los dos informes oficiales mencionados (Jadresic y Castillo) subrayan la lógica de coordinación que la Ley 19.300 estableció para la definición de la política ambiental y de los criterios normativos que ella conlleva. Las propuestas de mejora que hacen ambos informes vuelven a descartar la necesidad de un Ministerio del Medio Ambiente, tal como se había hecho en 1994, y vuelven a subrayar la necesidad de coordinar distintas competencias sectoriales. El hecho de que en ambos se proponga reducir la gran cantidad de ministros que hoy integran el Consejo Directivo no es contrario al objetivo de alcanzar tal coordinación. En la medida en que se deje a quienes mejor representen los distintos intereses que deben ponerse en juego al definir la política ambiental, esta reducción, con la ganancia en eficiencia que probablemente traería, puede entenderse como un refuerzo de

${ }^{7}$ Eso implica reformar, al menos, los artículos 70, 72 y 76 de la Ley 19.300.

${ }^{8}$ Castillo et al. (2000: 66-67). Hoy, los Comités Técnicos están presididos por el Director Regional de la Conama e integrados por los Directores Regionales de los Servicios Públicos que tienen competencia en materias ambientales, como, por ejemplo, el Servicio de Salud Metropolitano del Ambiente (Sesma), Servicio Agrícola y Ganadero (SAG), Dirección General de Aguas (DGA), Corporación Nacional Forestal (Conaf), Subsecretaría de Pesca, Servicio Nacional de Geología y Minería (Sernageomin), Servicio Nacional de Pesca (Sernapesca), Consejo de Monumentos Nacionales, Dirección Gobernación del Territorio Marítimo (DGTM), Dirección General de Aguas (DGA), Dirección de Vialidad, Servicio Nacional de Turismo (Sernatur). 
la lógica de coordinación. No sólo estos informes oficiales subrayan esta lógica. También lo ha hecho la evaluación internacional hecha a Chile por la OCDE (Informe OCDE, OCDE, 2005) y buena parte de la academia, como se verá a continuación.

El Informe OCDE es la evaluación internacional más extensa que se ha hecho sobre la experiencia ambiental chilena bajo la regulación de 1994. Publicado en el año 2005, pasa revista a las tres dimensiones de esta regulación. Como se verá más abajo, sus principales críticas se centran en la gestión de los recursos naturales y en la fiscalización. De hecho, respecto de estas dos dimensiones sugiere la posibilidad de reformas institucionales: un Ministerio en el caso de los primeros (como lo había hecho el Informe Jadresic en 1998) y una Superintendencia en el caso de la segunda. Pero en cuanto a la dimensión que aquí tratamos, es decir, en cuanto a política y normas ambientales, la OCDE no es especialmente crítica y comparte el tono generalmente positivo que su informe tiene sobre la experiencia ambiental chilena ${ }^{9}$. Apunta la misma carencia relativa de normas que denuncian las evaluaciones nacionales. Por ejemplo, dice: "faltan normas generales de emisiones para los procesos industriales y para los emisores de contaminantes tóxicos al aire (salvo el arsénico desde las fundiciones de cobre" (OCDE, 2005: 19). Y agrega: "No existen objetivos de calidad de agua orientados a la conservación de los ecosistemas, a pesar de que se están debatiendo" (2005: 21). Frente a estas carencias, recomienda: "desarrollar normas de emisión nacionales (por ejemplo, para un conjunto seleccionado de fuentes industriales y para contaminantes tóxicos del aire” (OCDE, 2005: 20, 36, énfasis en los originales).

No obstante estas carencias, y también de acuerdo con las evaluaciones nacionales, la OCDE no recomienda aquí un cambio en la lógica de coordinación que tiene el actual diseño institucional. Lo que hace, al igual que todas las evaluaciones en materia de política y normas ambientales, es sugerir un mejor aprovechamiento y profundización del diseño existente: "desarrollar y fortalecer aún más los marcos normativos (normas, entre otros) para mejorar la salud ambiental y cumplir los compromisos internacionales de Chile [...]" (OCDE, 2005: 18, 124, énfasis en el original).

${ }^{9}$ Este párrafo da una buena cuenta del tono generalmente positivo que tiene el informe, lo que ayuda a explicar el hecho de que, salvo en Recursos Naturales y fiscalización, no sugiera cambiar el modelo de coordinación actual, sino aprovecharlo mejor: "[Desde los años 1990] el país ha fortalecido sus instituciones ambientales sobre la base de un modelo de coordinación ambiental multisectorial. Además, ha intensificado sus iniciativas ambientales relativas al aire, el agua, los residuos y la gestión de la diversidad biológica, con instrumentos innovadores (comerciales, entre otros) y reformas exitosas (servicios relacionados con el agua, entre otros)" (OCDE, 2005: 15). 
Un año después de la publicación del Informe OCDE, y tras los anuncios de reforma a la institucionalidad ambiental que habían hecho los programas de gobierno en la elección presidencial del año 2005, Expansiva convocó a un grupo de profesionales para discutir sobre el punto. Figueroa y Hervé (2006), quienes intentan resumir las opiniones del grupo, señalan que fue opinión de la mayoría crear una autoridad ambiental "de alto nivel político y dedicación exclusiva” al medio ambiente, que especificaron como un ministro del medio ambiente, pero sin sugerir un Ministerio del Medio Ambiente ${ }^{10}$.

Es decir, la opinión de la mayoría de esos profesionales sólo busca crear una autoridad ambiental de mayor nivel político, y no un Ministerio que defina al medio ambiente como un sector específico de la administración. Así lo había propuesto el Informe Jadresic y este grupo de profesionales lo vuelve a hacer: "La propuesta que aquí formulamos constituye un paso intermedio entre la situación actual y la creación de un Ministerio del Medio Ambiente”. La valoración del modelo coordinador está detrás de este "paso intermedio": "Esta propuesta... genera el apoyo de la mayoría, en la medida que mantenga un modelo institucional coordinador y transectorial [...] no debe abandonarse un modelo de autoridad ambiental coordinadora, sino que, más bien, este debe perfeccionarse”. La manera en que éste se perfeccionaría es mediante este "paso intermedio" que representa la figura de un ministro:

[...] la figura de un Ministro del Medio Ambiente, con dedicación exclusiva, con recursos humanos y financieros suficientes a nivel nacional y regional, y con dependencia directa del Presidente de la República, permitiría dotar a la gestión ambiental del país de la prioridad política necesaria, superar la desarticulación entre las diversas instituciones con competencias ambientales, y liderar efectivamente la coordinación entre ellas. (Figueroa y Hervé, 2006: 5-6.)

Ahora bien, y desde el punto de vista de la fiscalización, este grupo de profesionales sí sugirió cambiar el modelo de coordinación a la hora de fiscalizar. Al igual que el Informe Jadresic, mantiene la coordinación para hacer la política ambiental y sus criterios normativos, y trata de reforzarla.

${ }^{10}$ De la opinión de minoría, que estaba por un Ministerio del Medio Ambiente, fue Sara Larraín. Ella parte, con todo, de un diagnóstico de la situación actual cuya radicalidad es también minoritaria: según sus palabras, estaríamos ante el "descrédito definitivo de la institucionalidad ambiental” (Larraín, 2006: 6). Poco después, la idea de un Ministerio también fue propuesta por Barton et al. (2007). 
Pero reemplaza este modelo por uno centralizado para la fiscalización. Sobre esto se vuelve más abajo.

Pareciera que, al menos en parte, el deseo de este grupo de profesionales fue satisfecho. La Ley 20.173, publicada a fines de marzo del año 2007, creó el cargo de Presidente de la Conama y le dio el rango de ministro. No creó un Ministerio del Medio Ambiente, pero dio el “paso intermedio”: creó una autoridad política de rango ministerial. En otras palabras, sentó a la autoridad ambiental en el Gabinete. Pero el Gobierno de la Presidenta Bachelet ha querido ir más allá y ha propuesto al Congreso lo que casi nadie había pedido: un Ministerio del Medio Ambiente.

\subsection{El proyecto de ley}

El Mensaje con que el Gobierno mandó al Congreso este proyecto de ley reconoce un hecho bastante cierto de nuestro ordenamiento jurídico: tenemos una administración pública de un carácter más bien "vertical”. En otras palabras, se ordena en "sectores" a cargo de distintos Ministerios, entendidos como Secretarías de Estado. También señala que la lógica de coordinación que subyace al actual sistema Conama-Corema le da a este sistema un carácter "transversal”, no vertical. A juicio del Mensaje, esto es dificultoso y le dirige una crítica: "las dificultades que presenta una institución transversal en una Administración pública vertical”"11.

Para solucionar esto, es decir, para solucionar las dificultades que enfrentaría un sistema transversal en un escenario vertical, el proyecto de ley propone un Ministerio. ¿Qué significa esto? ¿Se está “verticalizando” la regulación ambiental, constituyendo al medio ambiente en un sector de la administración pública al dedicarle una Secretaría de Estado?

Éste sería un paso mayúsculo, sobre todo considerando la amplitud de la definición legislativa de medio ambiente que tenemos: "El sistema global constituido por elementos naturales y artificiales de naturaleza física, química o biológica, socioculturales y sus interacciones, en permanente modificación por la acción humana o natural y que rige y condiciona la existencia y desarrollo de la vida en sus múltiples manifestaciones” (Art. 2, Ley 19.300). Esta enorme amplitud, que abarca no sólo las interacciones de los humanos con la naturaleza, sino que también las interacciones de los humanos entre sí (al hablar de elementos “naturales y artificiales”, y de elementos “socioculturales”), haría muy difícil hacer “vertical” su administración. Hay que considerar, además, que en lugar de reducir la amplitud de esta defini-

${ }^{11}$ La misma idea en Cordero (2006: 335). 
ción legislativa, como ocurre en regulaciones comparadas más avanzadas, el proyecto de ley la amplía aún más. Esto, pues a todo lo que ya contiene, le añade estas preocupaciones indígenas:

Los órganos del Estado, en el ejercicio de sus competencias ambientales y en la aplicación de los instrumentos de gestión ambiental, deberán propender por la adecuada conservación, desarrollo y fortalecimiento de la identidad, idiomas, instituciones y tradiciones sociales y culturales de los pueblos, comunidades y personas indígenas, de conformidad a lo señalado en la ley y en los Convenios internacionales ratificados por Chile y que se encuentren vigentes ${ }^{12}$. (Énfasis agregado.)

Frente a estas amplitudes, el proyecto de ley no osa crear una Secretaría de Estado que constituya un sector bajo ella. Si hubiese querido hacer eso, el proyecto de ley habría concentrado las competencias normativas y de política ambiental que se encuentran hoy dispersas. No lo hace, pues deja vivas estas competencias sectoriales. Lo que hace es crear una Secretaría de Estado para coordinarlas: un Ministerio que “coordina” a otros Ministerios, que “colabora” con ellos.

Así se lo encomienda el proyecto de ley: “Colaborar con los Ministerios sectoriales en la formulación de los criterios ambientales que deben ser incorporados en la elaboración de sus políticas y procesos de planificación, así como en la de de sus servicios dependientes y relacionados”. Y, más específicamente sobre competencias normativas, le encarga: "Coordinar el proceso de generación de las normas de calidad ambiental, de emisión y de planes de prevención y/o descontaminación, determinando los programas para su cumplimiento” (énfasis agregado). El hecho de que aquí no busca verticalizar la administración del medio ambiente con este Ministerio también queda claro al observar los demás verbos rectores con que se define su competencia respecto de los Ministerios que tienen hoy competencia ambiental: “proponer” y "participar”.

Al no verticalizar el medio ambiente bajo el Ministerio que propone, el proyecto de ley mantiene la lógica de coordinación que, en la definición de la política y normas ambientales, caracteriza a nuestra regulación desde

12 Otras regulaciones limitan lo que se va a regular en nombre del medio ambiente a: contaminación, residuos peligrosos, y protección de la fauna y flora silvestre. Es la definición que, por lo demás, Chile ha suscrito en sus compromisos internacionales. Por ejemplo, en el Nafta. Para el caso específico del acuerdo con Canadá, ver http://www.direcon.cl/documentos/COOPERACION\%20AMBIETAL TEXTO\%20DEL\%20ACUERDO.pdf Para una crítica de la definición de medio ambiente en la Ley 19.300, véase Bermúdez (2007: 53-4). 
1994. Lo que hace es trasladar el ejercicio de esta lógica desde el actual sistema Conama-Corema a un Ministerio del Medio Ambiente. ¿Profundiza y mejora este proyecto la actual lógica de coordinación, como lo vienen sugiriendo las distintas evaluaciones nacionales y extranjeras? No lo hace, por un par de razones, al menos.

La primera tiene que ver con la tradición: no parece haber Ministerios “coordinadores" en el Gabinete chileno. Los titulares de Ministerios representan a sus sectores y se sientan en la mesa del Gabinete como pares. El único Ministerio coordinador es la Secretaría General de la Presidencia, pero esto se explica por el hecho de ser una secretaría legislativa, destinada a coordinar la actuación del Gobierno como colegislador. No se trata, propiamente hablando, de un Ministerio que tenga que ver con contenidos "sectoriales"13. Si se aprueba este proyecto de ley, el Ministerio del Medio Ambiente será la primera Secretaría de Estado, con contenidos sectoriales, a la que se le asigna un papel coordinador. Esto se verá raro en una forma de Gobierno presidencialista, como es la chilena, pues la existencia de un Ministerio de Medio Ambiente es más propia de las formas parlamentarias de Gobierno, en las que la coordinación entre los distintos sectores es facilitada por su propia dinámica política ${ }^{14}$. En nuestra forma de Gobierno, por tanto, no hay una tradición que respalde la presencia de un Ministerio que, comprometido con materias sectoriales, "coordine” a otros Ministerios.

La segunda razón tiene que ver con el hecho de que el proyecto de ley mantiene el procedimiento de formulación de política y normas ambientales, pero elimina el Consejo Directivo de la Conama. Si el proyecto se aprueba, por tanto, en dicho procedimiento participarán el Ministerio del Medio Ambiente y el Ministerio sectorial que corresponda (por ejemplo, el Ministerio de Salud en el caso de las Normas "Primarias" de Calidad Ambiental, y el Ministerio de Agricultura en el caso de Normas "Secundarias" de Calidad Ambiental). Esto implica que la política y normas ambientales

${ }^{13}$ En el Gabinete hay autoridades con rango de Ministro, cuyo papel es coordinar a los demás Ministerios. Pero no son titulares de Ministerio. Éste es el caso de los titulares del Sernam, de la Comisión Nacional de Energía, de la Corfo y, desde hace poco, de la Conama.

${ }^{14}$ De hecho, todos los países que el Mensaje del proyecto ley menciona como ejemplos de países con Ministerios de Medio Ambiente "importantes”, son parlamentarios: Japón, Holanda, Nueva Zelanda, Australia, Austria, Bélgica, Canadá, Hungría, Italia, Luxemburgo y Turquía. También buena parte de aquellos con "Ministerios con competencias de regulación de la protección ambiental", pero que "integran facultades en gestión de algunos recursos naturales: Suecia, Grecia, Irlanda, Noruega, Alemania, Finlandia, Reino Unido y Corea. Se excluyen Francia, Colombia, Costa Rica, Brasil, y Suiza. Por último, los países con "Ministerios con mayores niveles de integración en gestión y recursos" también son parlamentarios: República Checa, España, Polonia, Portugal, Dinamarca. Sólo se excluye México. 
dejarán de definirse en el escenario multilateral que hoy debería ser el Consejo Directivo de la Conama, y pasarán a serlo en el escenario bilateral de la negociación a dos bandas entre el Ministerio del Medio Ambiente y el Ministerio sectorial respectivo.

Probablemente, esto traerá algunas consecuencias negativas. Por lo pronto, dificultará en grado sumo la concurrencia de los distintos puntos de vista e intereses que deben sopesarse para llevar bien a cabo la dimensión política y normativa de la regulación ambiental. Esta tarea requiere un escenario multisectorial para llevarse bien a cabo. El escenario que propone el proyecto de ley no es multilateral, sino que bilateral. Está diseñado para que el Ministro del Medio Ambiente negocie con cada Ministerio que tiene competencias ambientales. Es un escenario de dos, no de varios. Esto incentiva una situación de "gallito” entre los negociadores, que será agravada por la definición amplísima de medio ambiente que usa la Ley 19.300. En un escenario de negociación multilateral, como el que hoy existe, la posibilidad de "gallito" resulta diluida en su carácter colegiado. Aunque parezca paradójico a primera vista, un escenario bilateral, como el que se propone, generará mayores costos de transacción que los que puede generar uno multilateral. El "gallito" conlleva un costo de transacción potencialmente ilimitado. Éste, de seguro, se convertirá en un dolor de cabeza permanente para quien ocupe la Presidencia de la República, pues se verá, permanentemente, en la necesidad de zanjar el "gallito"15.

La propuesta de este Ministerio del Medio Ambiente con funciones coordinadoras de otros Ministerios, pero con una lógica bilateral y no multilateral, es, quizás, la peor parte de la reforma que este proyecto de ley ha iniciado. Sus otras dos partes — la creación de un Servicio de Evaluación Ambiental y de una Superintendencia Ambiental—, si se piensan bien, pueden ser oportunidades de mejora. El Ministerio del Medio Ambiente, en cambio, parece una mala idea desde el inicio: cuesta pensar en un Ministerio “coordinador”, menos si el ámbito de competencia tiene la amplitud que tiene el concepto de medio ambiente que usa nuestra legislación.

Hacia el final de este trabajo se propone una alternativa para mejorar la dimensión de política y normas de la regulación ambiental. Es una alternativa que intenta mejorar la lógica de coordinación definida en 1994, sin crear un Ministerio del Medio Ambiente. Esta propuesta va, además, en el senti-

${ }^{15}$ Esto, quizás, puede tener que ver con el hecho de que la mayor parte de las evaluaciones hechas en Chile no sólo no han pedido un Ministerio del Medio Ambiente. Algunas, incluso, han rechazado expresamente la idea: “...el Ministerio del Medio Ambiente no resuelve nada”. En cambio, según la misma evaluación, "Pareciera una idea razonable explorar la existencia de una agencia independiente con una dirección superior colegiada..." (Cordero, 2006: 345, 347, énfasis agregado). 
do que ha planteado buena parte de las evaluaciones que de la experiencia chilena se han hecho. Antes, sin embargo, se revisará la evaluación de las otras dos dimensiones de la regulación ambiental: gestión y fiscalización.

\section{GESTIÓN}

Sobre esta dimensión hay muchas opiniones y, en muchos casos, son muy detalladas. Buena parte de éstas se concentra en el instrumento de gestión que ha sido más protagónico: la evaluación ambiental (el SEIA). Los otros instrumentos, básicamente, son: el manejo de los recursos naturales y los mecanismos de mercado como, por ejemplo, los bonos de emisión transables. Estos últimos, sin embargo, prácticamente no se han materializado en nuestro país ${ }^{16}$. En lo que inmediatamente sigue serán tratados, empezando por el SEIA.

\subsection{El Sistema de Evaluación de Impacto Ambiental (SEIA)}

\subsubsection{Evaluaciones nacionales y extranjeras}

Hasta este año 2008, el SEIA ha evaluado proyectos por más de 120.000 millones de dólares en Chile. Cabe apuntar que su vida ha sido más corta que la de la Ley 19.300, pues sólo desde 1997, año en que se dictó su Reglamento, es obligatorio. Desde entonces, la más amplia variedad de iniciativas privadas y públicas debe someterse a la evaluación de su impacto ambiental por medio de "Declaraciones" (DIA) o "Estudios" (EIA). El Informe OCDE (2005) evalúa positivamente la experiencia del SEIA: "Como herramienta preventiva, el sistema de EIA está bien establecido y ha demostrado ser activo e influyente” $(2005: 17,127)^{17}$. Sin embargo, en la operación de

${ }^{16}$ Existe un proyecto de ley que crea bonos de descontaminación, pero se encuentra desde el año 2003 sólo en los primeros pasos de la tramitación legislativa (Boletín 329012, Proyecto de Ley Sobre Bonos de Descontaminación). Mediante reglamento se han establecido algunos pocos instrumentos de mercado. Entre éstos se encuentran el programa de compensación de emisiones de material particulado en la Región Metropolitana (Decreto Supremo 4 de 1992, modificado por Decreto Supremo 16 de 1998, ambos del Ministerio de Salud) y uno de compensación de grandes emisores de dióxido de nitrógeno, también en la Región Metropolitana (En el “Plan de Prevención y Descontaminación” de 2003).

${ }^{17}$ Lo mismo dice el Mensaje del proyecto de ley: "Es necesario recordar que nuestro SEIA es uno de los más exitosos del mundo; además, es el que menos plazos de tramitación puede exhibir en términos comparados y frente al cual se han realizado importantes esfuerzos de mejoramiento a nivel de gestión". 
este SEIA parece haberse consumido buena parte de la energía de la regulación ambiental. Es corriente oír entre los especialistas la crítica de que esta regulación se ha seaizado. Esto, en perjuicio de las otras dos dimensiones de la regulación, es decir, la política ambiental y la fiscalización.

Esto quiere decir que toda la regulación ha operado, en buena parte, alrededor de la evaluación ambiental. Casi toda la atención del Consejo Directivo habría estado puesta en reclamaciones interpuestas a propósito de Estudios de Impacto Ambiental, y no en la definición de política y de sus criterios normativos. Esta desatención con la política habría generado una secuencia negativa, pues su falta o retraso produciría un desincentivo en los Ministerios sectoriales para dictar sus normas ambientales, y esta falta o retraso de las normas, a su vez, aumentaría la discrecionalidad con que se toman las decisiones en el SEIA y en los procedimientos de fiscalización. Al respecto, Gianni López, quien fue Director Ejecutivo de la Conama entre 2001 y 2004, dice:

[...] existe consenso en que el marco normativo ambiental es aún incompleto, en particular para las normas de calidad de medios como el agua y suelo, y en las normas de emisión atmosférica. La regulación del uso del territorio rural, por su parte, si bien es de responsabilidad de otro sector, también afecta la gestión ambiental y es motivo de muchos de los conflictos que se observan en el SEIA. Los problemas del marco normativo no son atribuibles a la ley de medio ambiente, sino a la forma en que esta se ha implementado, porque el Poder Ejecutivo cuenta con todas las atribuciones para dictar normas. Esto ha motivado que las autoridades ambientales enfrentadas a la evaluación de los proyectos, principalmente a través de las Comisiones Regionales del Medio Ambiente, no observen sólo el rol de verificar si a priori existen garantías de cumplimiento de la normativa ambiental, sino que de hecho norman por su cuenta. Por ejemplo, habitualmente se emplea la facultad que otorga la ley de usar normas de otros países como referencia en aspectos que no están regulados en nuestro país, utilizándose fundamentalmente las normas suizas. Junto a lo anterior, se ha hecho un hábito aprobar los proyectos con un conjunto de otras exigencias de distinta naturaleza que, en opinión de la autoridad ambiental (principalmente regional), son útiles para mitigar y compensar sus potenciales impactos, muchas veces como una respuesta a la comunidad que se ha manifestado en contra. Todo lo anterior ha llevado a que tengamos un marco normativo por el cual a las guías que deben cumplir todas las actividades productivas se les superponga un sinfín de resolu- 
ciones de calificación ambiental concebidas y promulgadas caso a caso, indistintamente en las 13 regiones del país. Así, la coherencia entre las exigencias de las distintas regiones no está asegurada, e incluso si se observan al trasluz las resoluciones de calificación ambiental que aprobaron dos centrales de generación térmica, por ejemplo, es muy posible que se encuentren diferencias sustanciales entre ellas... este marco normativo es confuso para los inversionistas, y las exigencias ambientales que deberán cumplir dependen directamente de lo conflictivo que sea el proceso de evaluación de impacto ambiental que enfrenten. (López, 2006: 5-6.)

De este modo, la falta de normas ambientales sería suplida, en parte al menos, por las decisiones adoptadas en el SEIA. Es decir, en lugar de regularse el medio ambiente con normas generales y abstractas, como sería lo razonable, se estaría regulando mediante un conjunto de decisiones particulares, casuísticamente, sin la necesaria coherencia argumentativa. Al respecto, López enfatiza la necesidad de "ampliar el marco normativo: Priorizar, a base de la experiencia del Sistema de Evaluación de Impacto Ambiental y a base de la práctica internacional, las normas que logren llenar los vacíos normativos más recurrentes en la aprobación de proyectos, con el fin de evitar que estos se sigan resolviendo caso a caso en las distintas regiones de Chile” (2006: 6).

Un intento por revertir esta situación puede verse en el Informe Jadresic, pues releva al Consejo Directivo de la Conama de las obligaciones que hoy se le imponen respecto del SEIA. Así, liberados de esta tarea, los ministros podrían dedicarse más intensamente a definir la política ambiental y sus criterios normativos. A su vez, esta mayor actividad impulsaría a los distintos Ministerios a dictar las normas que expresen esos criterios. Esta mayor densidad normativa, por último, podría reducir la discreción en el SEIA. Lo mismo podría decirse de las demás propuestas revisadas más arriba, en el sentido de que todas quieren reducir el número de ministros en el Consejo Directivo. El objetivo de esto es agilizar la gestión política y normativa de este Consejo, y así desencadenar la secuencia señalada.

En las evaluaciones hechas a la gestión mediante el SEIA, por tanto, no hay una crítica a la lógica de coordinación que lo anima. Al contrario, se busca reforzarla, reforzando también la función de “ventanilla única” que opera en el SEIA. Al respecto, dice Lavín: "El sistema de ventanilla única proporciona una revisión omnicomprensiva de los proyectos de inversión y sus posibles efectos sobre el medio ambiente, en el sentido que, sin desconocerse las competencias específicas de los distintos servicios públicos, se pueden evaluar en su integridad y, con esa misma visión integral, determi- 
nar los permisos ambientales sectoriales que se deben obtener” (Lavín, 2006: 5). Tanto es así, que el proyecto de ley recién ingresado por el Gobierno, que hace desaparecer la lógica de coordinación en el diseño de la política ambiental, la reafirma a propósito de la gestión ambiental por medio del SEIA.

\subsubsection{El proyecto de ley}

En lugar del sistema Conama-Corema, el proyecto de ley propone un Servicio de Evaluación Ambiental, que se desconcentra territorialmente en Direcciones Regionales de Evaluación Ambiental. Para evaluar los proyectos, estas Direcciones Regionales tienen una Comisión para calificar las DIA y los EIA, que se integran así por diez Seremi: de Ambiente (la preside), Salud, Economía, Energía, Obras Públicas, Agricultura, Vivienda y Urbanismo, Transportes y Telecomunicaciones, Minería, Planificación. Secretario de esta comisión es el Director Regional del Servicio de Evaluación Ambiental. Como es evidente, la mirada multisectorial se mantiene. Se reduce el número de integrantes si se le compara con la cantidad que integran las Corema hoy, pero la lógica de coordinación entre sectores se preserva. Tiene otros problemas el proyecto en este punto, como se verá más abajo, pero es claro que no altera la lógica de coordinación.

Los informes Jadresic y Castillo apuntaron en el mismo sentido: ambos modifican la integración actual de las Corema, pero preservan la lógica de la coordinación a la hora de la evaluación de impacto ambiental. El Informe Jadresic quiere en la evaluación ambiental al Intendente Regional (preside) y a los Seremi de Economía, Salud, el de Recursos Naturales Renovables cuya creación sugiere, y un representante de la Secretaría Ejecutiva de Conama como Secretario Ejecutivo. El Informe Castillo, por su parte, no saca al Intendente de la integración vigente, pero sí a los Gobernadores, Consejeros Regionales y Seremi cuyos Ministerios forman parte del Consejo Directivo de la Conama, pero que no tienen efectivamente competencias ambientales; y quiere incorporar, como lo hace el proyecto de ley, a los Directores Regionales de servicios públicos con competencia ambiental y al Gobernador Marítimo correspondiente.

Las propuestas de reforma de la gestión ambiental mediante el SEIA, entonces, no van por el lado del diseño institucional en que se refleja la lógica de la coordinación. Más bien intentan hacer más operativa esta lógica, no cambiarla. El proyecto de ley, por tanto, va en la línea de lo que se ha propuesto. Y lo hace transformando al SEIA en un servicio sujeto al sistema de Alta Dirección Pública. Esto, en principio, no parece una mala idea. La 
Alta Dirección Pública no asegura independencia política de los funcionarios frente al Gobierno, si esto es lo que el proyecto de ley busca, pero sí garantiza una cierta capacidad y competencia en dichos funcionarios. No es poca cosa.

El problema parece estar en determinar qué autoridades deberían participar en la evaluación ambiental. El proyecto de ley elimina a los Intendentes, Gobernadores, representantes de los Gobiernos Regionales y a varios Seremi, dejando a un grupo de diez Seremi. El principal riesgo que esto sugiere, es el efecto centralista que tendría la eliminación de todos los representantes más claramente locales, además del riesgo de perder un cierto principio de autoridad que hoy representa la presencia de los Intendentes en las Corema.

\subsection{Gestión de los recursos naturales}

\subsubsection{Evaluaciones nacionales y extranjeras}

De acuerdo a las evaluaciones que se han hecho de la regulación ambiental chilena, éste parece ser uno de sus puntos más débiles. Buena parte de las críticas, nacionales y extranjeras, advierte sobre la deficiente manera en que estos recursos serían gestionados. Javier Vergara, por ejemplo, sintetiza la experiencia que se ha tenido en la gestión de los recursos naturales como la "gran deuda" de la regulación vigente: "La gran deuda de la situación ambiental actual está en los criterios de manejo y conservación de los recursos naturales. Estos han quedado bastante huérfanos de una adecuada y moderna regulación ambiental, principalmente en los ámbitos de flora y fauna terrestre" (Vergara, 2006: 3).

Desde el punto de vista del diseño ambiental, la competencia directa por la gestión de los recursos naturales está repartida en distintos Ministerios, por ejemplo, Bienes Nacionales, Economía, Agricultura, Obras Públicas y Defensa. Esta regulación tiene algunos problemas: hay ámbitos de competencia superpuestos y, en caso de conflicto entre ellos, no hay formas institucionales para resolverlos. Por ejemplo, la relación entre Bienes Nacionales y Agricultura a propósito de los "Santuarios Naturales” en que hay bosque nativo. Por otra parte, la competencia al interior de algunos Ministerios estaría expuesta a intereses contrapuestos, pues, se dice, estas competencias tienen facultades de "fomento" y de "protección". Por ejemplo, Agricultura y Economía. Estos Ministerios deben aportar a las cuentas nacionales, maximizando la producción, pero también están a cargo de conservar los bosques nativos y las pesquerías. 
Ya el Informe Jadresic propuso una reforma radical de la regulación sobre los recursos naturales. Propuso agrupar las competencias hoy dispersas en un Ministerio de Recursos Naturales Renovables. Es interesante el hecho de que el Informe Jadresic no haya propuesto un Ministerio del Medio Ambiente, pero sí este otro Ministerio para los recursos naturales renovables ${ }^{18}$. La arquitectura de este Ministerio se puede ver en el Gráfico № 1 .

La idea era que este Ministerio reemplazara al actual de Bienes Nacionales y absorbiera las competencias que hoy tienen Economía, Agricultura y Obras Públicas. A su vez, y como se vio más arriba, el ministro de Recursos Naturales Renovables pasaba a integrar y presidir el nuevo Consejo de Ministros que el Informe Jadresic propuso para definir la política y las normas ambientales.

Las evaluaciones internacionales también acusan un problema con los recursos renovables. En el Environmental Performance Index de 2008, de las universidades de Yale y Columbia (Esty et. al, 2008), por ejemplo, los indicadores vinculados más directamente a la gestión de estos recursos, como, por ejemplo, "biodiversidad y hábitat”, tienen una calificación más baja que otros indicadores ambientales, como, por ejemplo, la salubridad del medio ambiente.

El Informe OCDE también se refiere a la gestión de los recursos naturales, y lo hace en términos críticos. Dice al respecto:

Desde 1990, Chile ha experimentado un crecimiento económico rápido, crecientemente diversificado y liderado por las exportaciones, con un incremento del 108\% del PIB. Este desarrollo económico se ha apoyado en políticas macroeconómicas y sociales sólidas y ha tenido como consecuencia una reducción significativa de la pobreza. También ha ejercido una considerable presión sobre algunos recursos naturales, sobre todo en los sectores de mayor auge como la minería, la silvicultura y la acuicultura. (OCDE, 2005: 15, énfasis en el original.)

Luego, el Informe OCDE hace una crítica más específica:

Chile ha optado por un modelo de coordinación sectorial para organizar la gestión ambiental por el cual se asigna la responsabilidad de las actividades a los ministerios sectoriales y se establece Conama como entidad interministerial dependiente

${ }^{18}$ Esta precisión de "renovables" deja como está hoy la competencia sobre los recursos "no renovables”, como la minería, por ejemplo. 


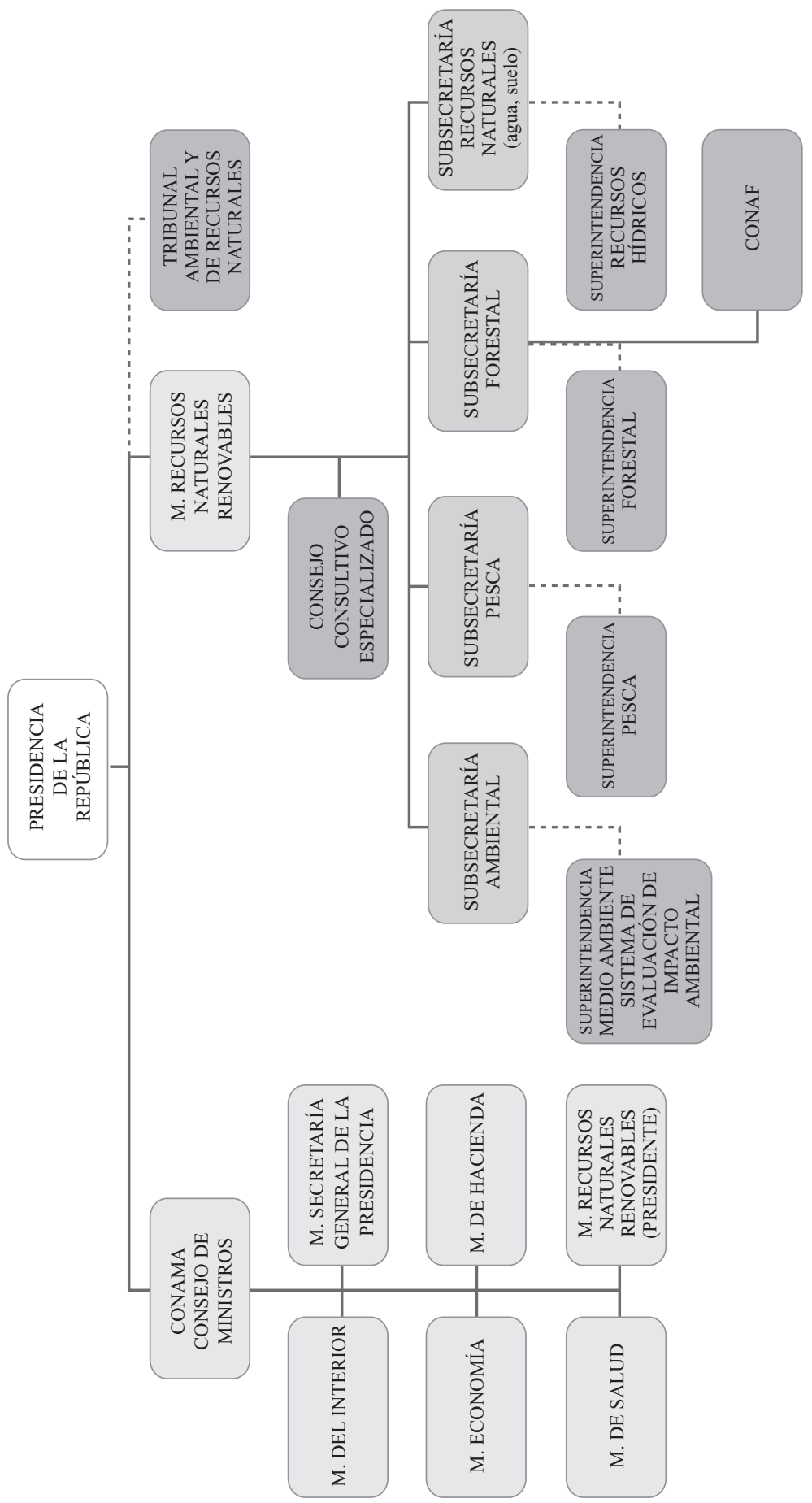


del Ministerio Secretaría General de la Presidencia en lugar de un ministerio de medio ambiente independiente. Este modelo puede funcionar tan bien como cualquier otro, siempre que todos los intereses estén representados y bien equilibrados. Sin embargo, en la práctica actual este modelo no toma en cuenta suficientemente que la protección de la naturaleza y la diversidad biológica van más allá de la gestión sustentable de los recursos naturales comerciables por parte de los organismos sectoriales que supervisan la agricultura, silvicultura, pesca, acuicultura, entre otros. A modo de ejemplo, los debates y las propuestas de financiamiento en pro de la naturaleza deben competir de forma inevitable con las agendas de desarrollo de las organizaciones sectoriales antes de llegar siquiera al Ejecutivo. (OCDE, 2005: 121, énfasis en el original.)

A partir de esta crítica, sugiere la posibilidad de un Ministerio de Recursos Naturales, aunque no del todo igual a como lo había sugerido antes el Informe Jadresic:

Una entidad dedicada a la protección de la naturaleza constituida al amparo de una ley de protección de la naturaleza completa y única que sea responsable de la protección de los hábitat terrestres y marítimos, de la protección de las especies y de los programas de recuperación, así como de la diversidad biológica tendría más probabilidades de éxito que la estructura actual, con sus vacíos y transposiciones. (OECD, 2005: 121.)

Como lo sugirió el Informe Jadresic, el titular de este Ministerio debería sentarse en el Consejo Directivo de la Conama, pero, a diferencia de él, la OCDE sugirió mantener las actuales competencias sectoriales. Dice: "Las entidades sectoriales seguirían asumiendo la tarea de gestionar de forma sustentable los recursos naturales comercializables de sus respectivos ámbitos” (OCDE, 2005: 121). Sería un Ministerio encargado de ayudar en la definición de la política y normas relativas a los recursos naturales o, como lo dice el informe, de constituirse en "una voz clara dentro del gobierno a favor de la naturaleza y la diversidad biológica” (OCDE, 2005: 121). Pero no absorbería las competencias de gestión de los sectores actualmente competentes. La competencia del Ministerio de Recursos Naturales propuesto por la OCDE, por tanto, parece ser de menor envergadura que la del Ministerio propuesto por el Informe Jadresic.

Después del Informe OCDE no se ha vuelto a hablar de un Ministerio de Recursos Naturales Renovables. A partir del año en que se publicó, 2005, la discusión política giró hacia tener un Ministerio del Medio Ambien- 
te, no uno de Recursos Naturales. Sólo Sara Larraín habló de nuevo sobre la institucionalidad de los recursos naturales un año más tarde, el 2006. Ella también sugiere un Ministerio del Medio Ambiente, pero una de las dos Subsecretarías que propone para él es la de "Recursos Naturales y Biodiversidad". La otra es la Subsecretaría de Medio Ambiente (Larraín, 2006: 22).

Una manifestación normativa de los problemas con la gestión de los recursos naturales es la práctica que existe con los "Planes de Manejo" que contempla la Ley 19.300. Éstos parecen no tener una autoridad responsable bien definida, y parecen estar rodeados de mucha discrecionalidad a la hora de su elaboración.

\subsubsection{El proyecto de ley}

No obstante esta extendida crítica respecto del actual estado de cosas con la gestión de los recursos naturales, el proyecto de ley que ha enviado el Gobierno propone harto poco al respecto. No hay sugerencia sustantiva alguna de rediseño institucional. Y las sugerencias que sí hay parecen un tanto cosméticas, pues se limitan a integrar al propuesto ministro del Medio Ambiente en el proceso de gestión, sin garantía alguna de que esto vaya a remediar las deficiencias ampliamente diagnosticadas, como la superposición de competencias, la tensión entre facultades de "fomento" y de "protección", y la orfandad de los Planes de Manejo, entre otras.

Las reformas que aquí propone el proyecto de ley son, básicamente, las siguientes, ordenadas por los distintos Ministerios que hoy tienen competencias sectoriales:

- Economía. En materia de recursos marinos, la declaración de Parques y Reservas Marinas debe hacerse mediante Decreto del Ministerio del Medio Ambiente. La declaración de una Reserva Marina como medida de protección de recursos hidrobiológicos debe hacerse por Decreto con las firmas de los ministros de Economía y de Medio Ambiente. Por último, las medidas de protección ambiental destinadas a que los establecimientos que exploten concesiones o autorizaciones de acuicultura operen en niveles compatibles con las capacidades de los cuerpos de agua lacustres, fluviales y marítimos, deben dictarse por Decreto con las firmas de los mismos ministros citados.

- Monumentos Nacionales. Los sitios declarados "Santuarios de la Naturaleza” pasan a quedar bajo la "custodia” del propuesto Ministerio 
del Medio Ambiente. Además, se propone que este Ministerio reemplace al de Agricultura en la declaración de ciertos "Parques Nacionales".

- $\quad$ Agricultura. Se precisa el ámbito de competencia del Ministerio de Agricultura en el sentido de que se extiende a la protección de los recursos naturales renovables del ámbito "silvoagropecuario".

- Bienes Nacionales. En el caso de que el Ministerio de Bienes Nacionales imponga medidas de protección ambiental a un poseedor de algún título sobre terrenos fiscales rústicos, el propuesto Ministerio del Medio Ambiente debe informar en forma previa. Además, en el caso de que el Ministerio de Bienes Nacionales decida destinar a otros usos los terrenos fiscales declarados "Reservas Forestales" y "Parques Nacionales", debe contar con un informe previo favorable del propuesto Ministerio del Medio Ambiente.

- $\quad$ Obras Públicas. En materia de aguas, se sugiere que el Reglamento que defina el "caudal ecológico mínimo" debe llevar la firma del ministro de Obras Públicas y del ministro del Medio Ambiente. En cuanto a los servicios sanitarios, se propone precisar el ámbito de competencia de la respectiva Superintendencia en el sentido que controla los residuos líquidos industriales que se encuentren "vinculados a las prestaciones o servicios de las empresas sanitarias".

Como se ve, en materia de gestión de recursos naturales el proyecto de ley no parece estar a la altura de lo que la regulación chilena, según las evaluaciones nacionales e internacionales, demanda. Pasemos ahora a la tercera y última dimensión regulatoria ambiental: fiscalización.

\section{FISCALIZACIÓN}

\subsection{Evaluaciones nacionales y extranjeras}

Sobre esta dimensión converge la crítica más extendida. Desde hace tiempo se viene diciendo que la lógica de coordinación que se definió en 1994 para regular el medio ambiente ha fallado en las tareas de verificar el cumplimiento de las normas ambientales y de aplicar sanciones en caso de verificarse incumplimientos. $\mathrm{Y}$ desde hace tiempo, también, se viene sugiriendo agrupar las hoy dispersas facultades fiscalizadoras. Ya el Informe Jadresic sugirió, derechamente, una Superintendencia de Medio Ambiente. 
Como se vio en el Gráfico $N^{\circ}$ 1, esta Superintendencia se vincula con la Presidencia de la República a través del Ministerio de Recursos Naturales Renovables cuya creación propone ${ }^{19}$.

El Informe Jadresic parte del siguiente diagnóstico: “[...] en nuestro país la fiscalización ambiental es poco efectiva y en algunas áreas inexistente... no hay procesos fiscalizadores que mantengan una evaluación permanente e integral de los niveles de calidad ambiental del aire, agua, suelo, ni de variables tales como ruido, olores y otras formas de alteración de la calidad del entorno" (1998: 102). Frente a este negativo diagnóstico, sugiere concentrar competencias:

La concentración de la responsabilidad fiscalizadora del Estado permitiría materializar los siguientes beneficios: desarrollar una visión integral de la calidad del entorno, desarrollar métodos de evaluación y control que minimicen el costo y maximicen la efectividad del proceso fiscalizador, concentrando recursos en los aspectos de mayor urgencia e importancia y evitando duplicidades y vacíos, permitir la identificación nítida de una autoridad responsable, con atribuciones acordes a esa responsabilidad, asegurar la aplicación de criterios y niveles de exigencia equitativos a diversos sectores y en todo el país (Informe Jadresic, Jadresic et al., 1998: 103).

Asimismo y como también se pudo ver en el Gráfico № 1, el Informe Jadresic (104-106) propuso una serie de Superintendencias en relación con los recursos naturales renovables:

- $\quad$ Pesca. La primera asumiría parte de las competencias que hoy tiene la Subsecretaría de Pesca y todas las competencias del Servicio Nacional de Pesca (Sernapesca). Es decir, tendría la gestión de instrumentos sobre las pesquerías, la concesión de permisos y la fiscalización.

- Bosque Nativo y Explotación Forestal. Sería el órgano especializado en las tareas de administración de subsidios y de fiscalización, según las establece la legislación de bosques. Para esto, asumiría parte del personal y recursos de la actual Conaf. Además, se propone reformar esta última para que quede a cargo de administrar las áreas silvestres protegidas del Estado como "órgano ejecutor de una res-

${ }^{19}$ Esta Superintendencia estaría a cargo, también, del Sistema de Evaluación de Impacto Ambiental. Ver el Gráfico No 1. 
ponsabilidad del Ministerio de Recursos Naturales” y como órgano a cargo de los incendios forestales ${ }^{20}$.

- Recursos Hídricos. Esta Superintendencia reemplazaría a la actual Dirección General de Aguas en el Ministerio de Obras Públicas.

En la misma línea de crítica a la experiencia que en fiscalización ha tenido la regulación dictada en 1994, la OCDE en su informe de 2005 es especialmente explícita al criticarla. Y, así como lo hizo para la gestión de los recursos naturales, según se acaba de ver, la OCDE hace una recomendación de rediseño institucional. Éstas son las dos únicas recomendaciones de rediseño institucional que hace este informe. Pero la relativa a fiscalización es más enfática y concreta que la relativa a los recursos naturales. Dice el informe:

Una política de fiscalización de la normativa ambiental sobre la base de la coordinación de los órganos sectoriales de supervisión y control no es la solución institucional más eficaz para asegurar su cumplimiento (2005:18). [Y sigue]: La Conama tiene escaso control sobre el nivel de cumplimiento y fiscalización de la normativa ambiental por parte de las entidades sectoriales. Los órganos sectoriales cuentan con el personal y la capacidad técnica general para realizar las inspecciones sobre el terreno, pero sus actividades de supervisión relacionadas con el medio ambiente se pueden ver opacadas por otras labores y prioridades. El papel fiscalizador asignado a las administraciones sectoriales debería incrementarse en el ámbito regional, donde los costos de transacción y los conflictos de interés son bajos en comparación con los niveles central y local. (OCDE, 2005: 145.)

Ante este panorama, en fin, recomienda concentrar la fiscalización en un "órgano de inspección ambiental”, es decir, en una Superintendencia: “...examinar formas de fortalecer la capacidad de cumplimiento y fiscalización, incluso mediante reformas institucionales, como por ejemplo el establecimiento de un órgano de inspección ambiental. (OCDE, 2005: 18, énfasis en el original.)

${ }^{20}$ Es interesante la argumentación que el Informe Jadresic hace para mantener a la Conaf. Por una parte, reconoce "...lo inadecuado que resulta Conaf para administrar los instrumentos de fomento y regulación de la explotación de bosques”, pero a continuación reconoce que "tiene una evaluación pública positiva en cuanto a su rol de administración de áreas silvestres protegidas, activo que debe preservarse”. Con relación a los incendios forestales, el informe destaca el hecho de que Conaf "reúne la mayor experiencia existente en nuestro país en esta materia y en el control de incendios forestales. Más aún, la concentración y especialización en estas materias por sí mismas serán un factor de fortalecimiento inmediato" (Informe Jadresic, Jadresic et al., 1998: 105). 
Otros estudios han apuntado en la misma dirección. Por ejemplo, Vergara (2006), afirma:

Lo central hoy es crear un sistema de fiscalización ambiental serio y potente. Más importante que la existencia de un ministerio es la creación de un nuevo sistema de fiscalización que se haga cargo de controlar el cumplimiento de las diversas normativas ambientales y tenga la facultad de interpretarlas, absolver las consultas de los reguladores y dictar instrucciones sobre el cumplimiento de las normas legales y reglamentarias... En efecto, parece que, más relevante que tener un ministerio, es tener una institucionalidad fiscalizadora seria, aspecto donde deberían concentrarse los mayores esfuerzos. (Vergara, 2006:13-14, énfasis en el original.)

Por su parte, López (2006) también propone una Superintendencia, aunque enfocada en la fiscalización de las normas ambientales que se aplican a la "industria”. Para él es necesario:

[...] generar un único sistema de fiscalización de las normas ambientales aplicables a la industria, que considere como elemento central una comunicación ambiental periódica por parte de cada empresa con información sobre sus emisiones y descargas que estén afectadas por una norma. Para esto se debe establecer una institucionalidad responsable para definir las características de esta declaración, de recopilarla y de generar las condiciones que aseguren la calidad para la información. Tiene que ser una institución técnica y especializada que pueda abordar integralmente el control ambiental de las empresas, y que cuente con independencia del poder político $\mathrm{y}$ de las instituciones responsables del fomento productivo. Esta nueva institución deberá, además, contar con las atribuciones que le permitan aplicar las sanciones por incumplimiento. Como criterio de diferenciación respecto del conjunto de instituciones públicas que ya cuentan con atribuciones ambientales, este nuevo organismo debe tener la responsabilidad sobre las empresas y sus fuentes, manteniendo en las instituciones sectoriales el control de la calidad de los distintos componentes del medio ambiente, como aire, agua, suelo, flora y fauna. En el caso del aire, por ejemplo, el Ministerio de Salud puede seguir siendo responsable del monitoreo de su calidad y a la vez participar en el manejo de episodios críticos de alta contaminación, en tanto que la nueva institucionalidad fiscaliza las normas que regulan las emisiones atmosféri- 
cas de la industria, mientras controla en forma simultánea el resto de las normas ambientales que esas mismas empresas deben cumplir. (López, 2006: 6-7.)

López, además, sugiere que esta Superintendencia esté sometida al Sistema de la Alta Dirección Pública y dependa de un eventual Ministerio del Medio Ambiente (cosas que el proyecto de ley del Gobierno hoy propone), o, en defecto de este último, del Ministerio de Economía, “por ser este el único que tiene una vinculación más transversal con el sector productivo. Además, los problemas de incompatibilidad asociados al fomento que desarrolla este Ministerio debieran quedar resueltos por las condiciones de autonomía de la Superintendencia (López, 2006, 10-11) ${ }^{21}$.

La necesidad que tendríamos de una Superintendencia también es subrayada por Figueroa y Hervé (2006):

En lo que sí parece haber consenso es en la debilidad que tiene el actual modelo institucional en materia de fiscalización y sanciones administrativas. Ciertamente llevar la fórmula de la sectorialidad al terreno de la fiscalización parece restarle fuerzas al Sistema de Gestión Ambiental del país, por lo que cobra sentido la idea de establecer una "ventanilla única” de fiscalización, desvinculada de las coyunturas y sobre la base de una mayor credibilidad. (Figueroa y Hervé, 2006: 3-4.)

${ }^{21}$ López hace, además, varias sugerencias más específicas para la Superintendencia. Se subrayan las más relevantes: a la Superintendencia se le deberían transferir "las atribuciones de fiscalización ambiental de la industria que hoy tienen otras reparticiones públicas, comenzando por el control de las emisiones atmosféricas y de los residuos sólidos (actualmente radicadas en el Ministerio de Salud, de acuerdo al Código Sanitario) y el control de las descargas de residuos industriales líquidos (de responsabilidad de la Superintendencia de Servicios Sanitarios y de la Dirección de Territorio Marítimo de la Armada, DIRECTERMAR)"; se le debe dar la facultad de "acreditar a los laboratorios ambientales responsables de emitir informes de evaluación de la calidad de las distintas emisiones de las industrias, junto con la facultad de administrar un registro de laboratorios ambientales”; se debe crear también un "auditor de las resoluciones de calificación ambiental y otorgarle a la Superintendencia las atribuciones para su acreditación y seguimiento, junto con la administración de un registro de auditores ambientales”; se debe crear el “instrumento 'Declaración Ambiental Anual', que corresponde a la comunicación ambiental periódica por parte de las empresas señalada anteriormente, junto con la obligatoriedad de ser presentada en los formatos y condiciones que la Superintendencia defina”; se le deben transferir "desde los distintos ministerios, servicios y las Corema a la Superintendencia las atribuciones de sancionar por incumplimiento de las normas ambientales y de las resoluciones de calificación ambiental"; y se debe crear un "Laboratorio de Referencia para el control de los Laboratorios Ambientales mediante intercomparaciones y otros procedimientos definidos por la Superintendencia” (López, 2006: 11-12, énfasis agregado). 
Sobre esta crítica al carácter sectorial que hoy tiene la fiscalización ambiental, los autores también sugieren centralizarla en la forma de una superintendencia:

[A]lgunos autores proponen la creación de una autoridad fiscalizadora con cierto grado de autonomía, esto es, con un alto nivel de independencia de los sectores productivos y del poder político en sus decisiones. Otros, en tanto, sostienen que, más que crear un organismo autónomo al cual se transfieran las competencias fiscalizadoras, lo que se requiere es establecer un sistema único de fiscalización ambiental, integrado y transectorial, en el que el nuevo organismo fiscalizador, la "Superintendencia Ambiental", tenga facultades propias para investigar y sancionar el incumplimiento de las normas ambientales, pero sin suprimir las actuales facultades de fiscalización de los organismos sectoriales que se deberían fortalecer y coordinar por medio de esta nueva institución. Creemos que la reforma en esta materia debería ir dirigida en esta última dirección [...] Este organismo contaría al menos con facultades directas para dirigir la investigación por incumplimiento de las resoluciones que dicte la autoridad ambiental, específicamente las Resoluciones de Calificación Ambiental en el contexto del SEIA, sancionando en forma directa o remitiéndose al organismo sectorial respectivo para que aplique la sanción correspondiente. A su vez, se le podrían otorgar facultades indirectas para que, a solicitud de la autoridad ambiental y con el debido contrapeso institucional, fiscalice el cumplimiento de otras normativas de relevancia ambiental. (Figueroa y Hervé, 2006: 6-7.)

En 2007 fue publicado uno de los pocos estudios más empíricos sobre la fiscalización. Se trata de Lamas y Chávez (2007), quienes estudian la práctica fiscalizadora que coordinó Corema de la VIII Región sobre los proyectos aprobados por el sistema de evaluación de impacto ambiental entre los años 1999 y 2004. En otras palabras, analizó la fiscalización que se hizo, en el respectivo "Programa de Fiscalización Ambiental Regional”, de lo dispuesto en las Resoluciones de Calificación Ambiental (RCA).

La evaluación que ellos hacen es más bien negativa. El carácter coordinado por el sistema Conama-Corema, conforme al cual hoy fiscalizan los distintos órganos sectoriales, sería problemático. Esto, pues habría superposición de ámbitos de competencia, con dos efectos dañinos: la percepción por parte de los fiscalizados de estar siendo acosados por el Estado desde distintos flancos, por una parte, y una imagen de confusión institu- 
cional, por la otra. Asimismo, y más allá de la fiscalización de las RCA, el sistema Conama-Corema, parece tener pocas atribuciones para chequear y poner en orden la fiscalización que hacen estos órganos reguladores del cumplimiento de sus normas sectoriales. Esto mermaría el papel disuasivo que debe tener una correcta fiscalización. Dicen estos autores:

[...] existe un nivel de fiscalización de aspectos sectoriales que hace que el esfuerzo para inducir cumplimiento sea eminentemente de carácter multisectorial, lo cual se traduce de algún modo en superposición de acciones fiscalizadoras que podría ser percibido por la población regulada como una presión excesiva y señales poco claras de parte del (de los) regulador(es). Adicionalmente, más allá del proceso del SEIA, la Conama tiene escaso control sobre el nivel de cumplimiento y fiscalización de la normativa ambiental por parte de las entidades sectoriales. Como consecuencia, este diseño institucional de carácter multisectorial para la fiscalización puede también contribuir a mermar el poder disuasivo de la acción del Estado contra los infractores, imponiendo barreras para el logro de niveles adecuados de cumplimiento. (Lamas y Chávez, 2007: 236.)

Con todo, la coordinación fiscalizadora que hace el sistema ConamaCorema tendría, a juicio de los autores, algunas características positivas. Por ejemplo, daría una "transparencia” interna al trabajo fiscalizador “debido a que éste es de conocimiento de todos los servicios participantes" (Lamas y Chávez, 2007: 236). Pero las críticas al sistema siguen. Una relevante tiene que ver con la dimensión sancionadora de la fiscalización. Ésta sería de un casuismo exacerbado, generando una jurisprudencia tan diversa que reduciría excesivamente el carácter previsible que debe tener toda tarea fiscalizadora. Dicen al respecto:

La determinación de la multa no está basada en una metodología establecida, sino que, por el contrario, es una decisión que toma la Corema caso a caso en base a los antecedentes que se le presentan. En consecuencia, no existe necesariamente una relación conocida ex ante entre el tipo y/o magnitud de la infracción y la sanción, lo que implica, desde el punto de vista de un potencial infractor, la presencia de incertidumbre respecto a los niveles de las multas a ser aplicadas. (Lamas y Chávez, 2007: 235-236.)

Sin duda, aquí hay un problema: el casuismo es pura discrecionalidad y ésta, sabemos, puede ser fértil en arbitrariedad. También, los autores 
critican la poca estandarización informativa que hay en el proceso de fiscalización, lo que, en lugar de incentivar el aprendizaje, lo dificultaría. Dicen al respecto: “...sería deseable el diseño de fichas de fiscalización que den cuenta de los principales aspectos del proyecto que se observa en cada visita de inspección, a fin de que en la misma visita de fiscalización se constate el estatus de cumplimiento ambiental del proyecto" (Lamas y Chávez, 2007: 237).

Y otra crítica tiene que ver, claro, con la escasez de recursos con que se desenvolvería el proceso fiscalizador. Entre otras consecuencias negativas, esto determinaría que el gran medio probatorio a la hora de fiscalizar y sancionar sean las visitas visuales de inspección, complementadas por una "entrevista" con los encargados de la ejecución de los proyectos fiscalizados. Por lo general, no se toman muestras de los elementos del medio ambiente potencialmente afectados por las conductas fiscalizadas. Sobre este punto escriben: "En la práctica sólo se consideran aspectos ambientales señalados en la RCA que son de fácil verificación. En particular, no se toman muestras de agua, ni tampoco de residuos líquidos, u otros tipos de efluentes o emisiones, para propósitos de realizar análisis cuantitativos. Lo anterior no es posible, pues no se cuenta con el equipamiento requerido para ello" (Lamas y Chávez, 2007: 218). Obviamente, esto reduce la dimensión empírica que debe tener toda tarea fiscalizadora, en especial si concluye en una sanción.

\subsection{El proyecto de ley}

La reforma a la institucionalidad ambiental recientemente enviada al Congreso comparte este extendido diagnóstico negativo de la forma en que actualmente se fiscaliza. Afirma el Mensaje del proyecto de ley:

Una de las ideas centrales sobre las cuales descansan los sistemas de fiscalización ambiental en los países con buenos desempeños ambientales, es su utilidad para generar incentivos al cumplimiento. Hoy el modelo chileno actúa precisamente en sentido inverso. En efecto, es un sistema que carece de la definición de adecuados programas de fiscalización, de metodologías públicamente conocidas, con énfasis en la sanción y en la fiscalización en terreno, sin modelos de integración, ni siquiera para los instrumentos de expresión multisectorial, como es el caso del Sistema de Evaluación de Impacto Ambiental, Planes y Normas... La alta dispersión en materia de criterios de fiscalización se expresa también en grandes diferencias en las sanciones desde los distintos sec- 
tores, lo que claramente entrega una falta de certeza y de coherencia frente a la aplicación de la legislación ambiental. En síntesis, nuestro modelo de fiscalización es altamente ineficiente. Es necesario contar con una autoridad que unifique los criterios, procedimientos e incentivos de las normativas ambientales.

Para resolver estos problemas, el proyecto de ley, en concordancia con el grueso de evaluaciones que se han hecho de la experiencia fiscalizadora chilena, propone la creación de una Superintendencia del Medio Ambiente. El estatuto jurídico que le atribuye es el común de las superintendencias en nuestro sistema: un servicio público funcionalmente centralizado, con personalidad jurídica y patrimonio propio. Estaría sometida a la supervigilancia de la Presidencia de la República a través del Ministerio del Medio Ambiente que el mismo proyecto propone, y sujeta al Sistema de Alta Dirección Pública.

Si bien la decisión de crear una Superintendencia del Medio Ambiente parece un paso en la dirección correcta, la forma que le da a ella el proyecto de ley es insuficiente. Esto, pues la forma que ha dado a la Superintendencia no facilita la función "unificadora” que se pretende, y que se necesita para racionalizar la tarea de fiscalización ambiental, hoy afectada de una poco racional superposición de competencias sectoriales. El proyecto de ley mantiene demasiado vivas estas competencias sectoriales. Dice al respecto: "Los organismos sectoriales que cumplan funciones de fiscalización ambiental, conservarán sus competencias y potestades de fiscalización, de conformidad a lo establecido en la presente ley”.

En un sentido importante, la Superintendencia propuesta en el proyecto de ley no resuelve el problema de superposición que todos han criticado. Sólo en ciertos aspectos de la tarea fiscalizadora unifica, pero en otros parece sumarse, simplemente, a la superposición existente. ¿En qué aspectos unifica y en qué otros no?

Entre los que sí unifica, destaca el aspecto sancionador de la fiscalización. Dentro de las atribuciones de la Superintendencia, el proyecto de ley contempla la de "imponer sanciones de conformidad a lo señalado en la presente ley”. Y, luego, establece que le corresponderá “exclusivamente” sancionar respecto de las siguientes infracciones que se reproducen textualmente:

“a) Incumplimiento de las condiciones, normas y demás exigencias previstas en las Resoluciones de Calificación Ambiental (RCA);

b) La ejecución de proyectos y el desarrollo de actividades para los que la ley exige Resolución de Calificación Ambiental, sin contar con ella; 
c) El incumplimiento de las medidas e instrumentos previstos en los Planes de Prevención y/o de Descontaminación;

d) El incumplimiento por parte de entidades técnicas acreditadas por la Superintendencia, de los términos y condiciones bajo las cuales se les haya otorgado la autorización, o de las obligaciones que esta ley les imponga;

e) El incumplimiento de las normas e instrucciones generales que la Superintendencia imparta en ejercicio de las atribuciones que le confiere esta ley;

f) El incumplimiento de los requerimientos y medidas urgentes y transitorias que la Superintendencia resuelva de conformidad a esta ley, respecto de los titulares de proyectos y actividades sujetos al Sistema de Evaluación de Impacto Ambiental;

g) El incumplimiento de las leyes, reglamentos y demás normas relacionadas con las descargas de residuos líquidos industriales, que no sean competencia de la Superintendencia de Servicios Sanitarios;

h) El incumplimiento de los planes de recuperación, conservación y gestión de especies establecidos en la Ley N ${ }^{\circ} 19.300$;

i) El incumplimiento de los requerimientos de información que la Superintendencia dirija a los sujetos fiscalizados, de conformidad a esta ley;

j) El incumplimiento de los planes de manejo a que se refiere la Ley $\mathrm{N}^{\circ} 19.300$;

k) El incumplimiento de las obligaciones derivadas de las medidas provisionales previstas en el artículo 47;

l) El incumplimiento de la obligación de informar de los responsables de fuentes emisoras, para la confección del registro al cual hace mención la letra t) del artículo $3^{\circ}$ de la presente ley, $\mathrm{y}$

m) El incumplimiento cualquiera de toda otra norma de carácter ambiental que no tenga establecida una sanción específica”,

Así, respecto de las sanciones transcritas la Superintendencia ha sido revestida de "exclusividad". Pero en los demás elementos del proceso fiscalizador las atribuciones de la Superintendencia conviven con las distintas atribuciones fiscalizadoras sectoriales. Para coordinar esta convivencia, el proyecto de ley dispone dos mecanismos: los "programas” y "subprogramas” de fiscalización. Éstos definirían, todos los años, las "prioridades” de fiscalización para el correspondiente ejercicio anual. Las prioridades contenidas en los "subprogramas" son sectoriales, definidas por sus respectivos órganos sectoriales. Tanto "programas" como "subprogramas", sin embargo, son dictados por la Superintendencia. Los primeros con un panorama 
general de la fiscalización para el correspondiente año. Los segundos, con los detalles para cada sector.

Tanto "programas” como "subprogramas” fiscalizarían los siguientes estándares normativos:

- $\quad$ Resoluciones de Calificación Ambiental (RCA) para cada región, incluida la Metropolitana.

- $\quad$ Planes de Prevención y/o de Descontaminación para las diversas regiones en que ellos operen.

- $\quad$ Otros estándares normativos "que de conformidad a las instrucciones impartidas por la Superintendencia o lo dispuesto en la Ley $\mathrm{N}^{\mathrm{o}} 19.300 \mathrm{u}$ otros cuerpos legales den origen a actividades de fiscalización en materia medioambiental, de competencia de la Superintendencia”.

Para la confección de estos programas, los órganos sectoriales informan a la Superintendencia sobre sus prioridades. A la luz de ellas, la Superintendencia elabora un borrador que consulta de vuelta con los órganos sectoriales. Una vez recibida la respuesta de éstos, el Superintendente dicta las normas correspondientes. ¿Qué pasa si hay diferencias entre el criterio de la Superintendencia y el de los órganos sectoriales? ¿Qué pasa si éstos sienten que sus prioridades no fueron suficientemente recogidas por la Superintendencia? Si así lo sienten, ¿estarán incentivados después a ejercer bien sus facultades fiscalizadoras? ¿Podrá la Superintendencia forzarlos de algún modo a hacerlo? ¿Hay mecanismos institucionales para impedir la superposición de ámbitos de competencia?

No hay respuestas explícitas en el proyecto de ley a estas preguntas, aunque parece percibir la dificultad que ellas envuelven cuando ordena: "Las resoluciones que fijen los programas y subprogramas deberán garantizar adecuadamente la participación en la fiscalización de la Superintendencia y de los organismos sectoriales. Asimismo, deberán resguardar la debida coordinación entre ellas, evitando duplicidad de funciones” (énfasis agregado). La misma dificultad parece percibirse cuando se refiere a la materialización de las tareas fiscalizadoras:

La Superintendencia realizará la ejecución de las inspecciones, mediciones y análisis que se requieran para el cumplimiento de los programas y subprogramas de fiscalización, como también encomendará dichas acciones a los organismos sectoriales, cuando corresponda. Para estos efectos, la Superintendencia impartirá directrices a los mencionados or- 
ganismos sectoriales, informando, las acciones de fiscalización que éstos asumirán, los plazos y oportunidades para su realización y las demás condiciones pertinentes. A su vez, la Superintendencia deberá informar a los organismos sectoriales correspondientes la ejecución de sus inspecciones, mediciones y análisis respectivos, de manera de evitar duplicidad de funciones. (Énfasis agregado.)

El proyecto de ley, por tanto, parece carecer de un mecanismo institucional establecido para resolver la eventual tensión que se produzca entre la Superintendencia y los órganos sectoriales sobre la forma de diseñar y ejecutar la fiscalización. Sólo ordena “evitar” la duplicidad, pero esto es más una exhortación a la voluntad que un mecanismo institucional.

Tampoco se soluciona el punto por la vía presupuestaria, como podría haber sido una alternativa para institucionalizar mejor un mecanismo de solución de eventuales conflictos de competencia. El proyecto de ley contempla la "participación” de la Superintendencia en la elaboración de los presupuestos ambientales sectoriales, con el deber de "promover su coherencia” con la política ambiental nacional. También especifica que los “programas” y “subprogramas” deberán contener información presupuestaria. Pero, de nuevo, el proyecto de ley omite un mecanismo institucional que permita resolver las eventuales discrepancias con los órganos sectoriales ${ }^{22}$.

Y tampoco se establece bien este mecanismo institucional mediante otro camino posible: la interpretación. El proyecto de ley encarga a la Superintendencia "interpretar administrativamente" los siguientes estándares normativos:

- $\quad$ Las Normas de Calidad Ambiental y de Emisión.

- $\quad$ Las Resoluciones de Calificación Ambiental (RCA).

- $\quad$ Los Planes de Prevención y/o de Descontaminación.

Para elaborar esta interpretación, la Superintendencia debe pedir informes sobre sus criterios hermenéuticos a los órganos sectoriales, al Ministerio del Medio Ambiente que el proyecto de ley propone y al Servicio de Evaluación de Impacto Ambiental que también propone. En el caso de

${ }^{22}$ Por otra parte, el proyecto de ley ordena que las resoluciones con los "programas" y "subprogramas" de fiscalización tienen "el carácter de reservadas mientras se encuentren en ejecución”. Alejando Ferreiro ha llamado la atención sobre esto señalando dos cosas. Primero, que esta parte de la ley requerirá quórum calificado, por ser una excepción a la regla general de publicidad de los actos de la administración. Segundo, cuestiona la existencia de esta excepción por la vía de preguntar qué se quiere: ¿Aumentar con información el nivel de cumplimiento de la normativa ambiental, o sancionar? Es un punto interesante. 
las Normas de Calidad Ambiental y de Emisión, se le da a la Superintendencia la facultad de "uniformar" su interpretación. Aquí sí establece, por tanto, un mecanismo institucional para resolver eventuales tensiones entre su criterio y el de los órganos sectoriales. Pero este mecanismo se desvanece respecto de los otros estándares normativos: RCA, y los Planes de Prevención y de Descontaminación. Respecto de ellos, prevalece el criterio de los órganos sectoriales cuando su normativa está involucrada. Dice al respecto el proyecto de ley: "Cuando el instrumento señalado en el inciso anterior [RCA y Planes] contuviese aspectos normados sometidos a las facultades de interpretación administrativa del organismo sectorial respectivo, el informe solicitado tendrá el carácter de vinculante para la Superintendencia en relación a esa materia”.

Como el proyecto de ley además encomienda a los órganos sectoriales "supervisar el cumplimiento de las acciones de fiscalización contempladas en esta ley y las demás que rijan la materia específica”, la falta de un buen mecanismo institucional para resolver las eventuales tensiones entre la Superintendencia y dichos órganos arriesga el peligro de mantener el actual esquema superpuesto de ámbitos de competencia a propósito de la fiscalización ambiental. Todos, incluyendo el proyecto de ley, han criticado este esquema por poco racional. La creación de una Superintendencia parece un buen primer paso para introducirle racionalidad. Pero la forma que se le ha dado, una forma de convivencia con las competencias sectoriales y sin mecanismos institucionales de resolución de sus diferencias, no promete muchos beneficios y sí garantiza una serie de perjuicios. En estas condiciones, si la Superintendencia propuesta por el proyecto de ley no se mejora, parece preferible abstenerse de crear una Superintendencia y perfeccionar, en cambio, el actual mecanismo "coordinado" de fiscalización entre distintos Ministerios ${ }^{23}$.

\section{CONCLUSIÓN:}

\section{UNA PROPUESTA INSTITUCIONAL ALTERNATIVA}

Lo expuesto hasta ahora dice que la regulación ambiental definida en 1994 ha operado razonablemente bien, aunque tiene deficiencias que es necesario corregir. ¿ Se hace cargo de ellas el proyecto de ley? Hay que distinguir entre las tres dimensiones de la regulación ambiental que se han venido discutiendo.

${ }^{23} \mathrm{Y}$ en esta mejora más limitada se podrían contemplar algunas cuestiones positivas que contempla el proyecto de ley. Por ejemplo, la posibilidad de encargar a terceros calificados ciertas tareas fiscalizadoras. También los incentivos que establece para la autodenuncia, aunque para que éstos fueran realmente eficaces, la rebaja de la sanción debería ser automática en caso de autodenuncia y no, como señala el proyecto, sujeta a la discrecionalidad de la autoridad. 


\subsection{Definición de política y normas ambientales}

El problema básico parece ser la ausencia de buenos estándares normativos que permitan una regulación más predecible, menos casuística. En esto ha fallado el Consejo Directivo de la Conama, al cual la Ley 19.300 le encomienda producir esos estándares normativos. No lo ha hecho. Quizás porque ha sido consumido por el casuismo del Sistema de Evaluación Ambiental. Y también porque debe ser difícil poner de acuerdo a un grupo de 14 autoridades ministeriales, en especial si la voluntad política del Gobierno ha estado ocupada en otros asuntos, como parece haberlo estado. El proyecto de ley no parece resolver bien el problema. Sustituye el escenario de negociación multilateral que representa la forma de un Consejo Directivo con varios Ministerios y sin Ministerio del Medio Ambiente, por el escenario de negociación bilateral de este Ministerio, sujeto a una definición de medio ambiente amplísima, con cada uno de los demás Ministerios que siguen conservando su competencia ambiental.

Este trabajo se inclina por una solución alternativa, como la que se ha venido proponiendo desde el Informe Jadresic (Jadresic et al., 1998): un Consejo Directivo reducido, más ágil, sin Ministerio del Medio Ambiente. Apoyado por una secretaría competente, que podría ser una Dirección Ejecutiva de Conama mejorada, este órgano colegiado, multilateral, debería producir los estándares normativos que se necesitan. ¿Cuáles Ministerios deberían componerlo?

Ésa es una materia a discutir. Se han propuesto alternativas. Por ejemplo, el Informe Jadresic (Jadresic et al., 1998) sugiere los siguientes sectores: Interior, Secretaría General de la Presidencia, Economía, Hacienda, Salud y el nuevo Ministerio que ese informe propone: Recursos Naturales Renovables. Esto es, seis sectores. Un grupo de especialistas en el Centro de Estudios Públicos (CEP), por su parte, ha sugerido como sectores que deben participar en la definición de la política y normas ambientales, los siguientes: Economía, Salud, Hacienda, Interior y Medio Ambiente, si este Ministerio llegara a crearse. Esto es, cinco Ministerios ${ }^{24}$.

Para la definición de la política y normas ambientales, entonces, este trabajo sugiere un órgano colegiado, con el número mínimo de Ministerios necesario para representar bien los objetivos e intereses que requiere esta tarea normativa, y que cuente con una Secretaría Ejecutiva eficiente y competente. Esta propuesta excluye la creación de un Ministerio del Medio Ambiente, aunque sí acepta la posibilidad de un nuevo Ministerio de Recursos Naturales, que reemplazara a Bienes Nacionales. La posibilidad de que

${ }^{24}$ Estos especialistas son Gabriel del Fávero, Ricardo Katz, Leonel Sierralta y Javier Vergara. Se reunieron en el mes de abril de 2008. Lucas Mac-Clure estuvo a cargo del trabajo de secretaría. 
exista un Presidente de este órgano colegiado, con rango de ministro, como existe hoy en la Conama, es un punto que queda abierto a la discusión. En todo caso, por razones de economía y de eficiencia operacional, este trabajo se inclina por un número de integrantes que sea el mínimo posible, siempre y cuando resulten bien representados los distintos intereses a considerar. En este sentido, la autoridad en este órgano colegiado podría ser el nuevo ministro de Recursos Naturales, sin necesidad de un Presidente con rango ministerial. Y podría estar acompañado por los siguientes Ministerios: Salud, Economía, Interior y Hacienda.

Un modelo como el que representa este órgano colegiado es coherente con la lógica que tradicionalmente ha tenido el Gabinete en Chile y facilita el escenario multilateral que es necesario para balancear bien esos objetivos e intereses. Calza también con el diseño regulatorio vigente para el medio ambiente, por lo que se necesita menos energía para reformar. La apuesta del proyecto de ley por un Ministerio del Medio Ambiente, en cambio, no calza bien en el Gabinete presidencialista chileno, y reemplaza el escenario multilateral por uno bilateral que dificultará el buen sopesamiento de los distintos objetivos e intereses, pues fomentará situaciones de "gallito” entre el Ministerio del Medio Ambiente y cada Ministerio sectorial con competencias ambientales. Esto, de seguro, retardará la adopción de decisiones y, posiblemente, afectará su calidad técnica y eficacia. Habrá costos institucionales y, también, para el medio ambiente.

Ahora bien, en la propuesta alternativa que aquí se hace, ¿participa este órgano colegiado en la evaluación ambiental, a fin de que se puedan reclamar ante él algunas decisiones, especialmente sobre EIA? La respuesta, obviamente, dependerá de la forma que se dé al sistema de evaluación ambiental. Sobre esto se volverá un poco más abajo.

En todo caso, si el Gobierno insiste con la idea de crear un Ministerio del Medio Ambiente, parece del todo necesario modificar también la definición de medio ambiente del artículo 4 de la Ley 19.300, haciéndola más precisa. Esto reduciría el riesgo de “gallitos” bilaterales, pues los dos Ministerios involucrados en la negociación tendrían ámbitos de competencia más claros y distintos. Pero en vez de esto, el proyecto de ley hace todo lo contrario: aumenta aún más la generalidad de la definición, incluyendo además, expresamente, consideraciones indígenas. No parece sensato.

\subsection{Gestión}

\subsubsection{Sistema de Evaluación de Impacto Ambiental (SEA)}

Aquí la propuesta del proyecto de ley puede ser razonable. Transformarlo en un servicio sujeto al sistema de Alta Dirección Pública no parece, 
en principio, una mala idea. La Alta Dirección Pública no asegura independencia política de los funcionarios frente al Gobierno, si esto es lo que se busca con el proyecto de ley, pero sí garantiza una cierta capacidad y competencia en dichos funcionarios. No es poca cosa.

El problema parece estar en determinar qué autoridades deberían participar en la evaluación ambiental. El proyecto de ley elimina a los Intendentes, Gobernadores, representantes de los Gobiernos Regionales y a varios Seremi. En principio, esto no parece necesariamente una mala idea, salvo por el efecto centralista que amenaza al eliminarse todos los representantes más claramente locales, sin proponer otros.

El grupo de especialistas en el Centro de Estudios Públicos (CEP), por su parte, ha discutido una propuesta interesante para la evaluación ambiental. Ella supone tener normas que distingan con precisión entre las Declaraciones de Impacto Ambiental (DIA) y los Estudios de Impacto Ambiental (EIA) ${ }^{25}$. Con buenas normas, bastaría con que un órgano “técnico”, un Servicio, por ejemplo, decidiera qué proyectos deben ser ingresados a evaluación como DIA y cuáles como EIA. En el caso de las DIA, éste u otro servicio puede decidir sobre ellas, aceptándolas, rechazándolas o imponiéndole condiciones. En esta tarea, el servicio podría consultar con otros servicios públicos, a fin de iluminar mejor su decisión.

En el caso de los EIA, la experiencia enseñaría que, por su mayor complejidad, siempre existe la posibilidad de cuestiones no previamente regladas. No muchas, pero siempre existe la posibilidad de tener que aplicar criterios prudenciales al caso. A la luz de esto, se propone que el mismo servicio mencionado distinga si un EIA cumple o no con las normas establecidas. Si cumple, debe determinar si el proyecto presenta, además, algunos

${ }^{25}$ Como se sabe, las reglas existentes no son suficientes proveyendo criterios para decidir. Esto generaría discrecionalidad y, consecuentemente, una jurisprudencia un tanto errática. La descripción que sigue puede ser ilustrativa de esto: “...la Corema de la X Región... por resolución exenta $\mathrm{N}^{\circ}$ 279/98 estimó que la alternativa propuesta por el titular del 'Proyecto Celco Valdivia' como sistema de tratamiento primario y secundario del efluente líquido, asociado a la descarga a través de un emisario submarino en la bahía de Maiquillahue, no cumplía con todos los requisitos ambientales aplicables, rechazando dicha alternativa, e impidiendo su consecuente ejecución, aprobando en cambio la otra alternativa del sistema de tratamiento, primario, secundario y terciario del efluente líquido propuesta por el titular del proyecto, asociado a la descarga en el Río Cruces, ya que ésta sí se haría cargo apropiadamente de los efectos, características y circunstancias a que se refiere la letra b) del artículo 11 de la ley $N^{\circ} 19.300$. En cambio, tratándose del proyecto 'Complejo Forestal e Industrial Nueva Aldea', actividad productiva de similar objeto que la anterior, la Corema de la VIII Región, por resolución exenta Nº76/2005, calificó favorablemente el proyecto 'Obras Nuevas y Actualizaciones del CFI Itata', siempre y cuando el titular implementara su propuesta de construcción y operación de un emisario submarino que dirija al mar sus RILES, reduciendo a cero las descargas al Río Itata” (Sepúlveda, 2008: 129, n. 24). 
aspectos sobre los que hay que decidir, pero respecto de los cuales no hay normas suficientes para hacerlo. Si los presenta, la tarea evaluadora dejará de ser de aplicación de normas y pasará a ser de creación de normas. En consecuencia, el balance entre intereses distintos debe reaparecer, con el escenario multilateral que lo facilita. No se discutió una forma institucional específica para que esto ocurra, pero sí se avanzó una hipótesis respecto de los sectores que deberían estar involucrados: Economía, Salud, Hacienda, Interior y Medio Ambiente, si este Ministerio llegara a crearse.

En síntesis, esta investigación considera que la propuesta que hace el proyecto de ley sobre la evaluación ambiental es digna de atención. Establecer al respecto un servicio sujeto al Sistema de Alta Dirección Pública puede ser una buena idea. Podría complementarse con un espacio colegiado para resolver los EIA en los casos en que no se puedan resolver aplicando criterios contenidos en normas preestablecidas. En cualquier caso, es importante conservar una mirada local en dicho espacio colegiado y un cierto principio de autoridad para su buen funcionamiento.

¿Ante quién se debería poder reclamar por decisiones adoptadas en el proceso de evaluación de impacto ambiental? Como se mencionó más arriba, ésta es una pregunta que hay que discutir. Si se incorpora la lógica discutida en el CEP que distingue entre aspectos normados y no normados en los EIA, las reclamaciones podrían ser así. De la decisión que se pronuncie por la existencia de aspectos que no están normados, se podría reclamar ante la justicia ordinaria. Esto, pues se trataría de una calificación jurídica formal. De la decisión que rechace un EIA respecto del cual se haya declarado contener aspectos no normados, podría reclamarse ante el órgano colegiado encargado de la definición de política y normas ambientales, aludido más arriba.

Por último, y aunque suene obvio, es importante pensar junto a este tipo de mejoras orgánicas de la evaluación ambiental, las posibles mejoras procesales que se le podrían también hacer ${ }^{26}$.

${ }^{26}$ Se han mencionado varias. Por ejemplo, Gabriel del Fávero, en el Anexo del Informe Castillo, sugiere las siguientes: excluir del SEIA las iniciativas "pequeñas”, que tienen un impacto ambiental poco relevante; distinguir más claramente entre las DIA y los EIA, enfatizando la idea original en el sentido de que las DIA deben ser la regla general y de que éstas deben ser de un trámite expedito, sin que se conviertan, en los hechos, en EIA; precisar el papel y ámbito de competencia de los Comités Técnicos de las Corema, en el entendido de que se mantengan, naturalmente; vincular y coordinar más precisamente las RCA, por un lado, y los permisos sectoriales, por el otro (sobre todo respecto de las DIA, caso en el que la relación es más difusa); precisar mejor las características y requisitos de los permisos sectoriales; ponderar más activa y explícitamente los costos ambientales y los costos económicos; y mejorar la participación ciudadana en el SEIA (Informe Castillo, Castillo et al., 2000: 40, Anexo). Como se ve, una propuesta muy importante es distinguir claramente entre DIA y 


\subsubsection{Gestión de recursos naturales}

Ahora bien, respecto de la gestión de estos recursos, el proyecto de ley peca por omisión. A pesar de la elocuente crítica nacional e internacional al estado de cosas en relación con los recursos naturales, el proyecto aquí no hace nada, a excepción de las pocas modificaciones más bien cosméticas que se revisaron arriba. En estas materias hay una importante deuda, lo que exige y justifica una reforma importante.

Bajo esta luz, esta investigación se inclina por la propuesta que hicieron el Informe Jadresic (Jadresic et al., 1998) y el Informe OCDE (OCDE, 2005), en el sentido de que el Ministerio que se cree en Chile no sea de Medio Ambiente, sino de Recursos Naturales. Éste debería reemplazar a Bienes Nacionales y concentrar todas las competencias de protección sobre estos recursos, hoy repartidas entre, por ejemplo, Economía, Agricultura, Obras Públicas, Defensa y, por cierto, el de Bienes Nacionales. Las competencias de fomento, es decir, aquellas en virtud de las cuales el Estado incentiva actividades que usan recursos naturales no con fines de protección o conservación, sino que de crecimiento económico, deberían quedar radicadas en los respectivos Ministerios sectoriales. Además, este nuevo Ministerio podría estar encargado de las cuestiones relativas a biodiversidad, calentamiento global y hábitat natural.

El nuevo Ministerio de Recursos Naturales debería integrar el órgano colegiado, multilateral, que, según se propuso más arriba, estaría a cargo de la política y normas ambientales. El Sistema de Evaluación de Impacto Ambiental que se decida, así como la Superintendencia que se propone a continuación, podrían conectarse con este Ministerio.

\subsection{Fiscalización}

A diferencia de la primera dimensión regulatoria ambiental, que implica crear política y normas ambientales, esta tercera es claramente una tarea de aplicación de esas normas ya creadas. Es análoga a la tarea de un juez: la Superintendencia subsume hechos en normas o, si se quiere, aplica éstas a aquéllos. Y mientras más mecánica pueda ser esta aplicación, mejor, pues esto refleja el hecho de que el juzgador tiene bajos niveles de discrecionalidad. Por todo esto, la fiscalización no exige el balance de objetivos e intereses que sí exige la formulación de la política y de las normas ambientales. Tampoco exige, por tanto, el escenario multilateral en que ese balance resul-

EIA, y que se preserve en las primeras su carácter original: que se limiten a una declaración y que sean la regla general. De este modo, es un contrasentido la propuesta que hace el proyecto de ley al incorporar la participación ciudadana en los procesos para las DIA. 
ta facilitado. Este balance ya está contenido en las normas que la Superintendencia debe aplicar.

La Superintendencia, entonces, puede y debe ser un órgano concentrado. Y debe serlo en todos los aspectos de la fiscalización, no sólo en las sanciones. A diferencia del proyecto de ley, aquí se propone una Superintendencia que absorba todas las competencias fiscalizadoras desde los Ministerios sectoriales. Una concentración así podría racionalizar la situación actual, de una manera mucho más plausible que el tibio intento que aquí hace el proyecto de ley, tan tibio que parece ser mejor no crear un nuevo órgano, como la Superintendencia, y dedicarse a mejorar el esquema de “coordinación” que hoy existe entre distintos Ministerios para fiscalizar ambientalmente. Si se va a crear este nuevo órgano, debe ser concentrado.

Sería una Superintendencia poderosa, qué duda cabe. Por esto tendría que ser bien ajustada a fin de que no se exceda en contra de los regulados, generando desequilibrios institucionales dañinos. Su sujeción al Sistema de Alta Dirección Pública ayudaría en esto, como también un razonable régimen de recursos contra las decisiones de fiscalización, precisando al máximo posible en la ley los criterios para sancionar y para las demás actuaciones de la Superintendencia. Ésta no debe amenazar la certeza que a las personas pueda brindar la regulación ambiental. Al respecto, el proyecto de ley es censurable, aun en la forma deslavada que da a la Superintendencia que propone, pues la siguiente atribución de ésta tiene la potencia de debilitar las Resoluciones de Calificación Ambiental (RCA):

Suspender transitoriamente las autorizaciones provisorias de inicio del proyecto o actividad y autorizaciones de funcionamiento contenidas en las Resoluciones de Calificación Ambiental o adoptar otras medidas urgentes y transitorias, para el resguardo del medio ambiente, cuando la ejecución u operación de un proyecto o actividad genere impactos ambientales no permitidos o que impliquen un daño significativo para el medio ambiente, a consecuencia de incumplimientos graves de las normas y condiciones previstas en dichas resoluciones, o por la generación de efectos no previstos en la evaluación ${ }^{27}$.

En síntesis, el diseño institucional para la regulación del medio ambiente que este trabajo sugiere es el que muestra el Gráfico $\mathrm{N}^{\circ} 2$. Él se basa en una premisa básica de economía institucional: en un escenario abigarrado y superpuesto como el que hoy tenemos en materias ambientales, cualquier competencia que se cree debe reemplazar a otra existente.

27 Sin duda, la generación de efectos no previstos es muy problemática. Una posibilidad de encararla, manteniendo un equilibrio razonable entre protección ambiental y certeza de las RCA como títulos jurídicos, quizás sea por la vía de seguros ambientales. A partir de ciertas magnitudes, al menos. 


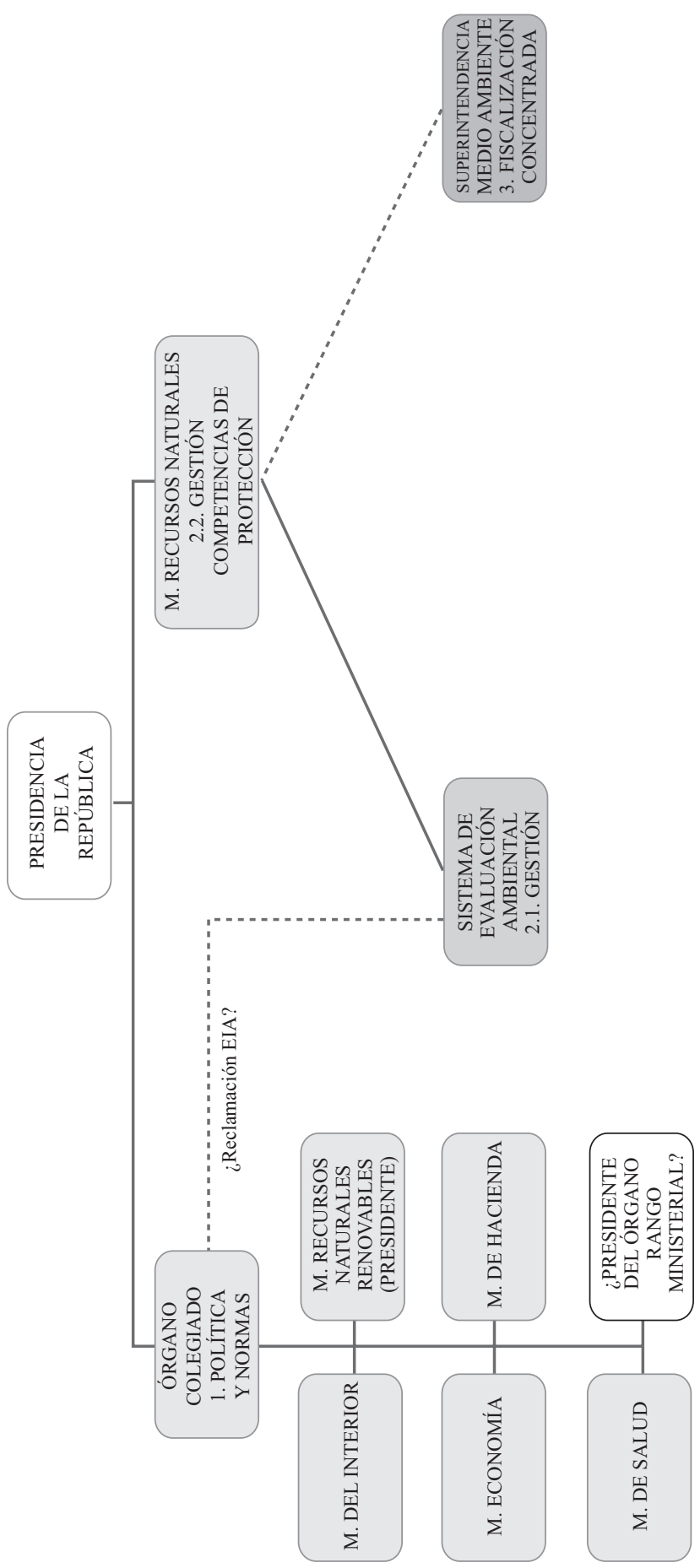




\section{REFERENCIAS BIBLIOGRÁFICAS}

\section{Informes Castillo, Jadresic y OCDE:}

Castillo Sánchez, Marcelo, et al. ( eds.) (2000): "Estudio de la Reforma de la Ley No 19.300 sobre Bases Generales del Medio Ambiente. Informe Final”. Santiago: Conama.

Jadresic, Alejandro et al. (1998): "Modernización de la Institucionalidad Reguladora del Estado. Informe Final. Protección del Medio Ambiente. Explotación de Recursos Naturales”. Santiago: Comisión Presidencial de Modernización de la Institucionalidad Reguladora del Estado. Documento no editado.

OCDE (2005): Evaluaciones del Desempeño Ambiental Chile. OCDE (Organización de Cooperación y Desarrollo Económico, y Comisión Económica para América Latina y el Caribe).

\section{Otras referencias:}

Asenjo, Rafael (2006): “Institucionalidad Pública y Gestión Ambiental en Chile”. En serie En Foco, Corporación Expansiva, Santiago.

Barton, Jonathan, Francisca Reyes y Sergio Galilea (2007): “El Nuevo Diseño de la Institucionalidad Ambiental en Chile. Informe Final”. Santiago: Universidad Católica de Chile, Subdere, Mideplan, Minsegpres.

Bermúdez, Jorge (2007): Fundamentos de Derecho Ambiental. Valparaíso: Ediciones Universitarias de Valparaíso, UCV.

Cordero, Luis (2006): "Las Paradojas de la Institucionalidad Ambiental o Cómo Debemos Diseñar Nuestras Instituciones”. En Facultad de Derecho de la Universidad de Chile, Institucionalidad e Instrumentos de Gestión Ambiental para el Chile del Bicentenario. Santiago: Facultad de Derecho de la Universidad de Chile, pp. 335347.

Del Fávero, Gabriel y Ricardo Katz (1998): "El Sistema de Generación de Normas de Calidad Ambiental y de Emisión”. En Estudios Públicos No 72 ( primavera), pp. 255-279.

Esty, Daniel C., M. A. Levy, C. H. Kim, A. de Sherbinin, T. Srebotnjak y V. Mara (2008): Environmental Performance Index. New Haven: Yale Center for Environmental Law and Policy. [Dsponible en http://epi.yale.edu/Chile]

Figueroa, Eugenio y Dominique Hervé (2006): "Evaluación del Marco Institucional y de la Gestión Ambiental en Chile”. En Serie En Foco, Corporación Expansiva, Santiago.

Lamas, Jaime y Carlos Chávez (2007): "El Sistema de Evaluación de Impacto Ambiental. Análisis del Diseño de Fiscalización y su Cumplimiento en la Región del Bío Bío”. En Estudios Públicos, № 105 (verano), pp. 205-239.

Larraín, Sara (2006): "Desafíos Ambientales del Desarrollo Nacional. Evaluación Desempeño 1997-2006 y Propuesta Institucional”. En serie En Foco, Corporación Expansiva, Santiago.

Lavín, Julio (2006): “El SEIA: Visión Crítica a 10 Años de su Vigencia”. En serie En Foco, Corporación Expansiva, Santiago.

López, Gianni (2006): "Propuesta de una Nueva Institucionalidad para la Fiscalización Ambiental de la Industria”. En serie En Foco, Corporación Expansiva, Santiago. 
Sepúlveda, Doris (2008): “Invalidación Sobreviviente de la Resolución de Calificación Ambiental por Modificación de su Presupuesto de Hecho”. En Durán et al. (eds.), Desarrollo Sustentable: Gobernanza y Derecho, Actas de las Cuartas Jornadas de Derecho Ambiental. Santiago: Facultad de Derecho de la Universidad de Chile, pp. 121-148.

Vergara, Javier (2006): “Criterios a Tener en Cuenta para la Discusión de una Política y una Institucionalidad Ambiental en Chile”. En Serie En Foco, Corporación Expansiva, Santiago.

Palabras clave: regulación ambiental; medio ambiente; política ambiental; gestión ambiental; fiscalización ambiental; recursos naturales.

Clasificación. JEL: I18; K32; Q20; Q50; Q57; Q58.

Recibido: septiembre de 2008; aceptado: septiembre de 2008. 